\title{
A Review of Potential Alternatives for Air Cleaning at the Hanford Waste Vitrification Plant
}

\author{
G. A. Sehmel
}

July 1990

Prepared for the U.S. Department of Energy under Contract DE-AC06-76RLO 1830

Pacific Northwest Laboratory

Operated for the U.S. Department of Energy

by Battelle Memorial Institute 


\title{
DISCLAIMER
}

This report was prepared as an account of work sponsored by an agency of the United States Government. Neither the United States Government nor any agency thereof, nor Battelle Memorial Institute, nor any of their employees, makes any warranty, expressed or implied, or assumes any legal Hbility or responsibility for the accuracy, completeness, or usefulness of any information, apparatus, product, or process disclosed, or represents that its use would not infringe privately owned rights. Reference herein to any specific commercial product, process, or service by trade name, trademark, manufacturer, or otherwise, does not necessarily constitute or imply its endorsement, recommendation, or favoring by the United States Government or any agency thereof, or Battelle Mernorial Institute. The views and opinions of authors expressed herein do not necessarily state or reflect those of the United States Government or any agency thereof.

\author{
PACIFIC NORTHWEST LABORATORY \\ operated by \\ BATTELLE MEMORIAL INSTITUTE \\ for the \\ UNITED STATES DEPARTMENT OF ENERGY \\ under Contract DE-AC06-76RLO 1830
}

Printed in the United States of America

Available to DOE and DOE contractors from the

Oifice of Scientific and Technical Information, P.O. Box 62, Oak Ridge, TN 37831 ; prices available from (615) 576-8401. FTS 626-8401.

Available to the public from the National Technical Iniormation Service, U.S. Department of Comınerce, 5285 Port Royal Rd., Springfield, VA 22161.

NTIS Price Codes, Microfiche A0I

Printed Copy

\begin{tabular}{ccccc}
\hline Price Code & Page Range & & Price Code & Page Range \\
\cline { 5 - 5 } \cline { 4 - 5 } A02 & $1-10$ & & A15 & $326-350$ \\
A03 & $11-50$ & & A16 & $351-375$ \\
A04 & $51-75$ & & A17 & $376-400$ \\
A05 & $76-100$ & & A18 & $401-425$ \\
A06 & $101-125$ & & A19 & $426-450$ \\
A07 & $126-150$ & & A20 & $451-475$ \\
A08 & $151-175$ & & A21 & $476-500$ \\
A09 & $176-200$ & & A22 & $501-525$ \\
A10 & $201-225$ & & A23 & $526-550$ \\
A11 & $226-250$ & & A24 & $551-575$ \\
A12 & $251-275$ & & A25 & $576-600$ \\
A13 & $276-300$ & A99 & $601-U p$ \\
A14 & $301-325$ & & &
\end{tabular}




\section{A REVIEW OF POTENTIAL ALTERNATIVES FOR AIR CLEANING AT THE HANFORD WASTE VITRIFICATION PLANT}

G. A. Sehmel

July 1990

Prepared for the U.S. Department of Energy under Contract DE-ACO6-76RLO 1830

Pacific Northwest Laboratory

Richland, Washington 99352 



\section{ABSTRACT}

Pacific Northwest Laboratory conducted this review in support of the Hanford Waste Vitrification Plant (HWVP) being designed by Fluor Daniel Inc. for the U.S. Department of Energy (DOE). The literature on air cleaning systems is reviewed to identify potential air cleaning alternatives that might be included in the design of HWVP. An overview of advantages/ disadvantages of the various air cleaning technologies follows. The scope of this overview does not include considerations of maintenance costs, personnel exposure, and decommissioning costs.

Alternatives to a deep-bed sand filter, the current design choice for HWV , are selected from existing technology suitable for the nominal airflow rate of $100,000 \mathrm{ft}^{3} / \mathrm{min}$ at HWVP. The current baseline filtration system for the Zone $l$ exhaust is a sand filter with a contact-maintained highefficiency particulate air (HEPA) filter downstream. Information on air cleaning alternatives is compiled from sources principally identified through a computer search of the DOE Energy Data Base. Many sources of interest are citations to the AEC/ERDA/DOE/NRC Nuclear Air Cleaning Conferences. Not all pertinent references identified are cited because of time constraints.

Information and references are presented for the following potential air cleaning alternatives: deep-bed glass-fiber filters (DBGF), high-efficiency particulate air filters (HEPA), remote modular filter systems, highefficiency mist eliminators (HEME), electrostatic precipitators, and the sand filter. Selected information is summarized for systems in the United States, Belgium, Japan, and West Germany. This review addresses high-capacity air cleaning systems currently used in the nuclear industry and emphasizes recent developments. 


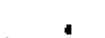




\section{SUMMARY}

An overview of advantages/disadvantages of potential air-cleaning technologies for Hanford Waste Vitrification Plant (HWVP) is summarized in the following table. The alternative air cleaning systems that appear feasible for HWVP include sand filters, high-efficiency particulate air (HEPA) filters, and deep-bed glass-fiber filters. All three are air cleaning equipment for high-capacity airflow systems. The remotely-operated modular filter units may be applicable, but several modular units would be required for an airflow capacity of $100,000 \mathrm{ft}^{3} / \mathrm{min}$ at HWV. The use of deep-bed glass-fiber filters would require research to identify non-crushable fibers that can be used in these filters. Although non-crushable fibers are used in the deep-bed glass-fiber filters at PUREX, this glass-fiber material is no longer available. The original loading of non-crushable fibers in PUREX is still in service for air cleaning.

TABLE S.1. An Overview of Advantages/Disadvantages of Potential Air Cleaning Technologies for HWVP

Technology

HEPA filters
Advantages

A nuclear industry standard for highefficiency air

cleaning

$99.97 \%$ efficiency for 0.3- $\mu \mathrm{m}$-diameter particles

Decontamination

factor, $D F=3 \times 10^{3}$
Disadvantages

Contact maintenance required.

Filters must be replaced at an administrative lifetime or sooner.

Filter damage can occur during installation, during lifetime, or upon over pressurization.

Mechanical strength of filter media degrades and ages over several years. 
IABLE S.1. (contd)

Technology

Sand Filter

Deep-Bed Glass-

Fiber Filters

Remote Modular Filters

Electrostatic Precipitation
Advantages

High-capacity dust

holding and airflow

cleaning system

Low maintenance

Efficiency can approach that of a single HEPA filter.

Design flexibility

to obtain desired

efficiency

Originally developed as alternative for sand filter

Filter element replaceable by remote hand $\mathrm{ing}$
High collection efficiency for submicrometer particles

Low pressure drop, hence low energy cost to move air
Disadvantages

One of a kind design.

Design depends on filtering efficiency of avaiTable sand/gravel.

High pressure drop affects costs for operation.

Efficiency needs to be determined as a function of particle diameter.

Requires identification of a noncrushable fiber.

Fiber-glass used previously at PUREX is no longer available.

Many modular units would be required for HWVP. Multiple units might increase costs.

$100,000 \mathrm{ft}^{3} /$ min capacity not used previousiy in

nuclear industry.

Guaranteed source of filter element required.

Operation not continuous for dry operation; down-time required to clean collector surfaces.

Not previously used in nuclear industry for high airflow capacity systems. Not fail safe during power failure. 
IABLE S.1. (contd)

Technology

High-Efficiency

Mist ET iminator

\section{Advantages}

Performance high for dry conditions; washable filter
Disadvantages

Material wicks "entrain" through fiTter if operated wet and at high face velocity.

High pressure drop. 



\section{CONTENTS}

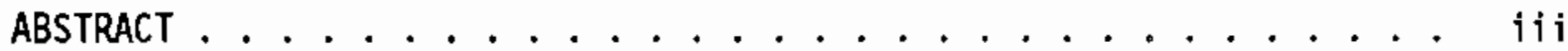

SUMMARY .........................

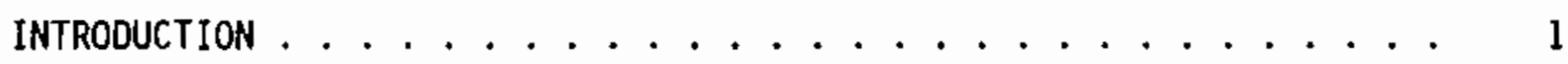

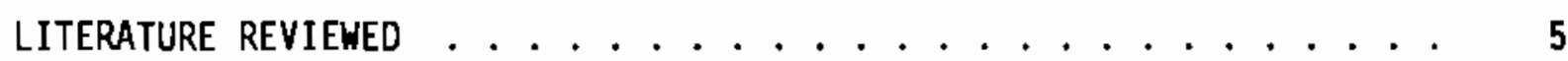

MECHANISMS OF AIR CLEANING .................. 9

STRAINING . . . . . . . . . . . . . . 9

IMPINGEMENT/INERTIAL DEPOSITION ................... 9

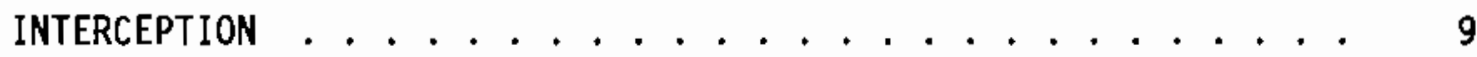

DIFFUSION ............................ 10

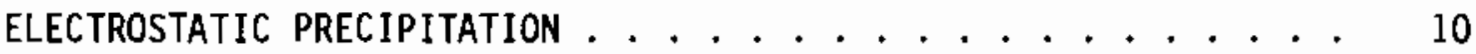

GENERAL DESCRIPTION OF AIR CLEANING EqUIPMENT. . . . . . . . . . 11

FABRIC FILTERS. . . . . . . . . . . . . . . 11

ElECTROSTATIC PRECIPITATORS . . . . . . . . . . . . 12

IONIZING WET SCRUBBERS. . . . . . . . . . . . . . . 14

OTHER AIR CLEANING EQUIPMENT . . . . . . . . . . . . . 15

FOREIGN VITRIFICATION PLANTS AND MODULAR AIR CLEANING SYSTEMS $\ldots . .17$

MODULAR AIR CLEANING SYSTEM IN EUROPE . . . . . . . . . . . 17

VITRIFICATION PLANT IN EUROPE .............. 17

VITRIFICATION PLANTS IN JAPAN ............... 18

ALternative Air Cleaning Methods ReVIEWEd . . . . . . . . . . . 19

SAND FILTERS .................................. 19

Layers in Sand Filters............. 20

Advantages/Disadvantages of Sand Filters........ 21

Installed Sand Filters for Air Cleaning . . . . . . . 23 
DEEP-BED GLASS-FIBER FILTERS . . . . . . . . . . . 23

Advantages/Disadvantages of DBGF Filters . . . . . . 26

Installed DBGF Filters ............ 26

HIGH-EFFICIENCY PARTICULATE AIR FILTERS . . . . . . . . 27

General Overview of HEPAs ............. 29

HEPA Installation ............... 30

Particle Penetration through HEPA Filters...... . 30

HEPA Degradation.................. 32

Filter Aging ................... 32

Survey of HEPA Performance . . . . . . . . . 32

Overpressure Failures of HEPAs .......... . 33

REMOTELY-OPERATED MODULAR FILTER UNITS ........... 34

Development of Optimum Internal Geometry of Filter

Housings ............... 37

Air Cleaning Applications ........... 37

PACKED-FIBER MIST ELIMINATORS . . . . . . . . . . . . 38

HIGH-EFFICIENCY MIST ELIMINATORS . . . . . . . . . . . 39

HEMEs at the Savannah River $\mathrm{Plant} \ldots . . . . . . . .40$

HEME Performance Tests . . . . . . . . . . . 42

Modular Self-Cleaning HEME ........... 42

CONCLUSIONS ............................. 45

REFERENCES ....................... 47

APPENDIX A - MISINTERPRETATION OF EARLY SAND FILTER PERFORMANCE. . . . A.I

APPENDIX B - PARTICLE INSTRUMENTATION FOR IN-PLACE TESTING . . . . B.1

APPENDIX C - IN-PLACE TESTING OF FILTERS . . . . . . . . c.1 


\section{FIGURES}

1 Section Through a Typical Sand Filter............. 21

2 General Isometric View and Details of Sand Filter At Savannah River Site............... . 22

3 Construction Details of Open-Face HEPA Filter . . . . . . . 27

4 General Effects of Principal Mechanisms that Affect Particle Collection Efficiency in HEPA Filters ........... 31

5. Remotely-Operated Filter Housing with HEPA Filter .......35

6 Comparison of Sizes and Arrangement of Filter Papers of Various Filter Elements Considered for Inclusion in Remote Modules . . . . . . . . . . . . . . . .

7 PASSAT Packed Fiber Mist Eliminator for Droplet Removal for Particle Diameters Less Than 10 Micrometers . . . . . . . . 39

8 Packed-Fiber Mist Eliminator, Comparison of the Filter Surfaces ................ 40

9 Self-Cleaning Demister ............... 43

\section{TABLES}

S.1 An Overview of Advantages/Disadvantages of Potentia] Air Cleaning Technologies for HWVP.............. v

1 AEC/ERDA/DOE Nuclear Air Cleaning Conferences . . . . . . . 6

2 Dimensions and Operating Data of Existing U.S. Sand Filters ......................... 24 


\section{INTRODUCTION}

The design basis for the Hanford Waste Vitrification Plant (HWVP) requires the best high-flow air cleaning system from existing technology. The Westinghouse Hanford Company HWVP Project Office requested the Pacific Northwest Laboratory (PNL) to review potential alternatives for air cleaning. Project personnel at HWVP will consider these alternatives in a "top down" approach to evaluate the best available radionuclide control technology (BARCT) $^{(a)}$ analysis for air cleaning.

HWV's current design basis is a deep-bed sand filter for the air cleaning system. The baseline filtration system for (Zone 1) exhaust is the sand filter with a contact-maintained high-efficiency particulate air (HEPA) filter downstream. Two other configurations considered by HWVP are 1) a twostage HEPA filter system remotely maintained in a separate facility and 2) prefilters at the cell exhaust (remotely maintained) with a two-stage contact-maintained HEPA filter system in a separate facility.

This review does not evaluate the BARCT analysis. It addresses available air cleaning technologies for potential use by HWVP, but does not address the $p l$ acement of these technologies into HWVP. Because HWVP requires a high-capacity airflow system, systems for low-capacity airflow and with low particle collection efficiencies are not reviewed. Some of these systems are in Moore's (1984) review of control technology for radioactive emissions to the atmosphere at U.S. Department of Energy (DOE) facilities.

Aspects to be considered in the selection and design of an air cleaning system include the following:

(a) The Washington State Administrative Code (WAC-402-80-020) defines BARCT as "technology which will result in a radionuclide emission limitation based on the maximum degree of reduction for radionuclides which would be emitted from any proposed stationary source or modification of a source which the permitting authority on a case-by-case basis, taking into account energy, environmental, and economic impacts and other costs, determines is achievable for such source or modification through application of production processes or available methods, systems, and techniques." 
- particle concentrations in inlet air

- degree of cleanliness required

- disposal of particles and system when the system becomes loaded or is no longer needed.

These features affect initial costs, operating costs, and maintenance costs. Criteria for equipment selection are that the collector 1) will allow the least amount of contaminant to escape, 2 ) is reasonable in cost and maintenance, 3) meets all prevailing, or anticipated, air pollution regulations, and 4) presents an acceptable risk as perceived by the public.

Air cleaning equipment must meet at least three major requirements to be considered as an alternative for use in the HWVP. The air cleaning equipment must have high efficiency for the most penetrating particle diameter (about 0.1 to $0.3 \mu \mathrm{m})$, have low contact maintenance, and allow safe and economical disposal. In addition, efficiency must be verifiable because of good engineering practice (in-place testing with tracer particles), and equipment must satisfy legal requirements for processing radioactive materials.

Alternatives for air cleaning include HEPA filters, used extensively in the nuclear industry, and other types of equipment that may prove best for use in HWVP. The scope of this review does not include the arrangement of multiple filters or types of equipment into the HWV design.

This review focuses on air cleaning methods that can remove airborne particles from a system that has an airflow capacity of $2833 \mathrm{~m}^{3} / \mathrm{min}$ $\left(100,000 \mathrm{ft}^{3} / \mathrm{min}\right)$, the nominal airflow at HWVP. Alternatives include recently developed remotely-operated modular air cleaning units configured into parallel operation to get the desired airflow capacity. Also, to develop a common basis to describe air cleaning alternatives, this review includes some background information on air cleaning mechanisms and lower airflow capacity systems. Design details are beyond the scope of this report. A constraint of this review is that all references must be publicly available.

After initial sections that describe the literature reviewed and provide a general description of filtration mechanisms and air cleaning devices, this 
report contains two major sections. The first is a description of foreign vitrification plants and air cleaning systems of potential interest to HWVP. The second is a summary of air cleaning methods reviewed: sand filters, deep-bed glass-fiber filters (DBGFs), HEPA filters, remotely-operated modular filter units, and high-efficiency mist eliminators (HEMEs). 
s 


\section{LITERATURE REVIEWED}

Air cleaning methods were reviewed to document methods that can be considered as alternatives to meet air quality standards for effluent from the HWVP. These a]ternatives are based on a literature review of air cleaning methods, usually identified through a computer search of the DOE energy data base.

Air cleaning methods sought in the literature review included the following:

- electrostatic precipitation

- deep-bed back-flushed filter

- deep-bed glass-fiber filter

- sand filter

- HEPA filter

- high-efficiency mist eliminator.

The deep-bed glass-fiber filter and high-efficiency mist eliminator are similar equipment; the difference is in the airflow capacity. In the context of this review, the deep-bed glass-fiber filter is a high-flow air cleaning system such as used in PUREX at Hanford. The deep-bed glass-fiber filter was developed prior to 1976 (Burchsted et al. 1976) as an alternative to sand filters. The high-efficiency mist eliminator is an air cleaning system for removal of mists. It is used primarily in systems with much smaller airflow capacity.

The words searched in the DOE energy data base and the number of references identified for initial review follow:

- deep bed -- 33

- electrostatic precipitation -- 1811

- HEPA air filter - - 302

- mist eliminator -- 4. 
In addition, specific words were selected to obtain information from recent developments in remotely-operated modular filters in Europe.

A total of 140 abstracts identified in the DOE energy data base were reviewed in more detail. Some documents identified were not obtained because of time constraints, including several documents written in German and published in Germany. Information from German sources is available in summary, however, because several authors also published in the Nuclear Air Cleaning Symposia sponsored by the Atomic Energy Commission (AEC), Energy Research and Development Administration (ERDA), DOE, and the Nuclear Regulatory Commission (NRC). This symposia series is concerned with applications of air cleaning methods/technologies to the nuclear industry.

AEC/ERDA/DOE/NRC Nuclear Air Cleaning Conferences and document numbers are listed by year in Table 1 through Conference number 20 , a conference in

TABLE 1. AEC/ERDA/DOE Nuclear Air Cleaning Conferences

\begin{tabular}{|c|c|c|c|}
\hline $\begin{array}{c}\text { Conference } \\
\text { Number }\end{array}$ & $\begin{array}{c}\text { Conference } \\
\text { Year } \\
\end{array}$ & $\begin{array}{c}\text { Conference } \\
\text { Location }\end{array}$ & $\begin{array}{c}\text { Document } \\
\text { Number }\end{array}$ \\
\hline $\begin{array}{c}1 \\
2 \\
3 \\
4 \\
5 \\
6 \\
7 \\
8 \\
9 \\
10 \\
\text { IAEA } \\
11 \\
12 \\
13 \\
14 \\
15 \\
16 \\
17 \\
18 \\
19 \\
20\end{array}$ & $\begin{array}{l}1951 \\
1952 \\
1953 \\
1955 \\
1957 \\
1959 \\
1961 \\
1963 \\
1966 \\
1968 \\
1968 \\
1970 \\
1972 \\
1974 \\
1976 \\
1978 \\
1980 \\
1982 \\
1984 \\
1986 \\
1988\end{array}$ & $\begin{array}{l}\text { Boston } \\
\text { Ames } \\
\text { Los Alamos } \\
\text { Argonne } \\
\text { Boston } \\
\text { Idaho Falls } \\
\text { Brookhaven } \\
\text { Oak Ridge } \\
\text { Boston } \\
\text { New York } \\
\text { New York } \\
\text { Hanford } \\
\text { Oak Ridge } \\
\text { San Francisco } \\
\text { Sun Valley } \\
\text { Boston } \\
\text { San Diego } \\
\text { Denver } \\
\text { Baltimore } \\
\text { Seattle } \\
\text { Boston }\end{array}$ & $\begin{array}{l}\text { no proceedings } \\
\text { WASH-149 } \\
\text { WASH-170 } \\
\text { TID-7513 } \\
\text { TID-7551 } \\
\text { TID-7593 } \\
\text { TID-7627 } \\
\text { TID-7677 } \\
\text { CONF-660904 } \\
\text { CONF-680821 (a) } \\
\text { CONF-680811 (a) } \\
\text { CONF-700816 } \\
\text { CONF-720823 } \\
\text { CONF-740807 } \\
\text { CONF-760822 } \\
\text { CONF-780819 } \\
\text { CONF-801038 } \\
\text { CONF-820833 } \\
\text { CONF-840806 } \\
\text { CONF-860820 } \\
\text { CONF-880822 }\end{array}$ \\
\hline
\end{tabular}

(a) Available from IAEA as STI-PUB- 195. 
1988. There are two indices to these Air Cleaning Conferences. Burchsted (1981) reports an index of the first 16 AEC/ERDA/DOE Nuclear Air Cleaning conferences. Jennings (1989) reports the most recent index, for the first through twent ieth AEC/ERDA/DOE and DOE/NRC Nuclear Air Cleaning Conferences.

other documents reviewed include books and publications by air cleaning system manufacturers and professional society. These include Cambridge and Flanders Corporations, two manufacturers of HEPA filters. The societies are the American Conference of Governmental Industrial Hygienists (ACGIH 1988), American Society of Heating, Refrigeration and Air Conditioning Engineers (ASHRAE 1988), Air \& Waste Management Association (AWMA 1981, formerly APCA), and the American Nuclear Society (ANS). Other documentation could be included in a more comprehensive review of air cleaning alternatives for HWVP, but a representative sampling of applicable air cleaning methods was reviewed in this study. 



\section{MECHANISMS OF AIR CLEANING}

The five basic methods of air cleaning are straining, impingement, interception, diffusion, and electrostatic precipitation (ASHRAE 1988; ACGIH 1988).

\section{STRAINING}

In straining systems, particle removal is based on filter openings being smaller than the particulate being renoved. Straining is effective for particles larger than the openings in the filter media. The straining mechanism is ineffective for particles smaller than the openings. Particle removal by straining is not an important removal process in a sand filter.

\section{IMPINGEMENT/INERTIAL DEPOSITION}

Inertial mechanisms depend on particle size and density. Particle inertia causes impingement of particles on collection surfaces. When air flows around fibers in a filter, the inertia of large particles prevents them from following abrupt changes in air direction. The large particles collide with the fiber and are removed from the air stream. However, when air velocities are too high (where inertial effects are most pronounced), particles may not adhere to fibers because of air drag forces. Filters designed on impingement/inertial processes are often coated with an adhesive to hold particles to the fiber.

\section{INTERCEPTION}

Interception occurs when particles following the air motion are removed from the airstream when they graze a fiber surface and are thus retained. Contact with fibers is dependent on particle size, but is nearly independent of velocity. After particle deposition, Van der Waals forces, i.e., adhesive forces between particles and fibers, cause particle retention on fibers. 


\section{DIFFUSION}

Diffusion is the primary mechanism used by most efficient filters for the removal of small particles or particles of negligible inertia. Particle transport by diffusion occurs when particle motion responds to molecular collisions of gases. Particle diffusion is a function of particle size; diffusion rates increase as particle size decreases. Particle deposition creates concentration gradients in the air near fibers, further enhancing filtration by diffusion across concentration gradients. After deposition, Van der Waals forces cause particle retention on surfaces.

\section{ELECTROSTATIC PRECIPITATION}

Electrostatic precipitation occurs because of attraction between charged particles and surfaces of opposite polarity. Airborne particles are charged in an ionization field. Particles collect on surfaces that are grounded or of opposite polarity. Under certain circumstances, electrostatic charges may be created within fibrous filter media, which usually assist particle collection. In addition, particles can induce an electrostatic charge of opposite polarity at the surface of the packing. The image force from this induced charge causes the particle to be attracted to the collection surface. 


\section{GENERAL DESCRIPTION OF AIR CLEANING EQUIPMENT}

ASHRAE (1988) lists basic types of air cleaning equipment. These are

- centrifugal collectors: cyclones, mechanical centrifugal collectors

- electrostatic augmented scrubbers

- electrostatic precipitators: tubular, plate, wet, dry

- fabric filters: baghouse, fabric collectors

- gravity and momentum collectors: settling chambers, louvers, baffle chambers

- wet collectors: spray scrubbers, impingement scrubbers, wet cyclones, venturis, packed towers, mobile-bed scrubbers.

Fabric filters, electrostatic precipitators, and ionizing wet scrubbers are described in more detail because they have attributes that may need to be considered in selection of the design basis for the HWVP air cleaning equipment.

\section{FABRIC FILTERS}

Fabric filtration equipment is the topic of a recent international symposium (AWMA 1989). Papers address commercial applications, but do not address nuclear air cleaning specifically. In discussing fabric filter trends, McIlvaine (1989) states that cartridge filters have transformed the fabric filter industry. The fundamental difference between fabric filters and cartridge filters is that the cartridge uses pleated media for collection; thus, the filter surface area is larger. Cartridges are more difficult to clean.

McIlvaine (1989) also reports development of filter media to remove smaller submicrometer particles, and suggests fabrics are coming closer to the performance of the micro-glass fiber HEPA filters. He does not discuss airflow capacities. These media (called Sintamatic material and developed by DOE) are sintered materials consisting of a patented blend of engineered composites. The potential applications of Sintamatic filtration include continuous operation in industries where safety, reliability and high filtration 
efficiency are important. These industries include pharmaceutical, food, chemical, and toxic material handling.

The Monsanto Brink HiEf(a) particle filter is a modular dust collector with high particle removal efficiency. The pleated filters are specially modified microfine glass fibers. Several modules can be used in a sequencecontrolled on-line cleaning system. Units can handle higher dust loads than replaceable type air filters, while providing higher collection efficiency than traditional fabric filter dust collectors.

Mcllvaine (1989) suggests that these new designs of high-efficiency filters will to some extent replace the two-stage filter now used for some of these applications. Typically a HEPA filter follows a conventional fabric filter.

Hall (1988) suggests that fabric filters are the main competitive process for electrostatic precipitators for fine particle collection. These are used in several low-to-medium gas temperature applications, mostly for sma11-to-medium size equipment and dry particle collection. Equipment size is qualitative. Hall uses the term "Targe" to describe many industrial applications, e.g., coal and oit-fired electric power plants, large industrial steam boilers, paper mills, cement plants, refuse incineration, chemical plants, and metallurgical processes.

\section{ELECTROSTATIC PRECIPITATORS}

Electrostatic forces remove airborne particles in electrostatic precipitators. Electrostatic precipitation is the topic of a recent international symposium (Rea 1988). Papers address commercial applications, but do not address directly nuclear air cleaning. Hal1 (1988) suggests that modern electrostatic precipitators perform reliably to obtain collection efficiencies 99 to $99.9+\%$ by weight (including micrometer and submicrometer diameter particles). Increasing emphasis is being placed in the 0 - to 5-km range and especially in the 0 - to 2 - $\mu \mathrm{m}$ range.

(a) Registered Trademark of Monsanto 
An advantage of electrostatic precipitators is the high removal efficiency for sub-micrometer diameter particles. Electrostatic precipitation removes particulate matter from a moving air stream by imparting a charge to particles in the stream and collecting them on oppositely charged surfaces. Particle removal is caused by a high electric field between discharge and collection electrodes of opposite electrical charge. The discharge electrode has a small cross-sectional area, and the collection electrode has a large cross-sectional area.

The electrostatic precipitation process has the following subprocesses:

- Ionize the gas.

- Charge the particles.

- Transport particles to the collection surface.

- Neutralize, or remove, charges from the particles.

- Remove collected particles from collection surfaces.

The air ionizes near the discharge electrodes. Ions with the same polarity as the discharge electrode attach to neutral particle in the gas flowing through the precipitator. These charged particles are attracted to the collection plates of opposite polarity. The particles lose their charge upon contact with the collection plates. Deposited particles can be removed by washing, vibration, or gravity.

The two basic types of electrostatic precipitators are "Cottre11," or single-stage, and "Penny," or two-stage. The Cottre 11 precipitator combines ionization and collection in a single stage. It is a high-voltage precipitator, air ionized at voltages from 40,000 to 70,000 volts $D C$. Cottrelltype precipitators usually are designed and custom built specifically for installations required to process large volumes of contaminated air (REA 1980). The Penny, two-stage, precipitator uses lower voltages, from 11,000 to 14,000 volts $D C$ for ionization.

The inlet gas stream may require air conditioning to help ionize the air stream. ACGIH (1988) suggests a cooling tower may be needed for high-voltage 
units. For low-voltage units, air conditioning is with wet scrubbers, evaporative coolers, heat exchanger, or other devices.

The pressure drop in an electrostatic precipitator is very low, usually less than one inch water gage $(w g)$. Because of the low pressure drop, energy costs to move the air are significantly less than for other air cleaning aiternatives.

\section{IONIZING WET SCRUBBERS}

Ionizing wet scrubbers (IWSs) are recent advanced technology for lowenergy gas cleaning (Griem 1988). Industriat applications include capacities up to $140,000 \mathrm{~m}^{3} / \mathrm{h}$. For removal of particles from a pyrite burning process, efficiencies for two-stage IWSs range from 96.5 to $98.5 \%$ for solids.

Ionizing wet scrubbers combine advantages of electrostatic precipitators and wet scrubbers. The IWS is a packed crossflow scrubber preceded by a high-voltage ionizer. Air flows horizontally through the scrubber, and the scrubbing liquid absorbs gases as it recycles from the top downward to the integrated sump. Particles are charged in the first section of the IWS while passing through a series of negative electrode wires and grounded electrode plates, which are 250 to $300 \mathrm{~mm}$ wide. Liquid continuously flushes these plates to prevent build-up of a resistive layer of particles. After particle charging, airflow is through an electrically neutral packed bed irrigated with scrubbing liquid ('Tellerette' is the packing). Particles greater than about $3 \mu \mathrm{m}$ diameter are removed by impaction. Particles smaller than about $3 \mu \mathrm{m}$ diameter collect by electrostatic image forces.

Griem (1988) compares particle collection efficiency as a function of particle size in an IWS with that in common electrostatic precipitators and fabric filters. For common electrostatic precipitators, efficiency drops in the $0.2-$ to $0.6-\mu m$ size range. In fabric filters, filter efficiency decreases sharply when particles are $0.5 \mu \mathrm{m}$ and smaller. He suggests that in an IWS the collection efficiency decreases only slightly for these particle sizes. 


\section{OTHER AIR CLEANING EQUIPMENT}

Other air cleaning collectors used in industrial operations do not seem suitable as air cleaning options for HWV. These other collectors include wet collectors and dry centrifugal collectors. There are many publications on air cleaning devices for industrial applications. Additional references include, but are not limited to, Calvert and Englund (1984), Martin (1981), Ogawa (1984), and REA (1980). 



\section{FOREIGN VITRIFICATION PLANTS AND MODULAR AIR CLEANING SYSTEMS}

Air cleaning systems used at vitrification plants throughout the world are alternatives that should be considered for HWV. Vitrification plants identified are one site in Europe (PAMELA) and two sites in Japan.

Dissolver off-gas cleanup systems are also applicable because of similarities to air cleaning systems used in vitrification processes. Remotelyoperated modular air cleaning systems are recent methods developed in Europe for treatment of dissolver off-gases; modular systems contain either HEPA filters or packed-bed filters.

\section{MODULAR AIR CLEANING SYSTEM IN EUROPE}

PASSAT, an industrial-scale reprocessing plant, uses remotely-operated modular filter units for air cleaning (for dissolver off-gas) at the WAESCHE simulation facility at the Karlsruhe Nuclear Research Center (Kernforschungszentrum Karlsruhe, KfK, West Germany, Jannakos et al. 1989). PASSAT contains remotely-handled filter components for a gas throughput of 50 to $250 \mathrm{~m}^{3} / \mathrm{h}$ (Furrer et a1. 1983). Major components of the system include packed-fiber mist eliminators (a modular unit). The packed-fiber is a single annular filter contajned within the remote module (Jannakos et al. 1987).

\section{VITRIFICATION PLANT IN EUROPE}

The PAMELA plant, based on a liquid-fed ceramic melter process, is at the reprocessing plant EUROCHEMIC (Centre d'Etude de $1^{\prime}$ Energie Nucleaire) at Mol, Belgium. A joule-heated ceramic melter at PAMELA vitrifies high-level waste. The PAMELA melter design is the design selected for the West German reprocessing plant in Wackerdorf (wiese et a1. 1987). PAMELA is a pilot plant to demonstrate the production of glassblocks and glassbeads embedded in Tead.

Fiber glass filters housed in remotely-operated modular filter units are used at the PAMELA vitrification plant (Wiese et al. 1987). These filter units are the final cleanup system before effluent air exhausts through HEPA filters. 
The gas cleaned by these remotely-operated modular units (at this point of the process) is air, nitric-acid aerosols, and particulates. Two HEPA filters in series treat this airstream (the air is heated to $70^{\circ} \mathrm{C}$ ). After cooling to $30^{\circ} \mathrm{C}$, blowers discharge the gas to the stack. This fiber glass filter unit is described in more detail in the vitrification section on remotely-operated modular filter units (see description of remotely operated filter housing on p. 33).

\section{VITRIFICATION PLANTS IN JAPAN}

Vitrification plants in Japan use wet type or wet water-filmed electrostatic precipitators (WEP) for air cleaning (Sasaki et al. 1987; Kitamura et a1. 1987). Kitamura et al. (1987) report some details of the electrostatic precipitator.

Sasaki et al. (1987) describe the vitrification process under development by the Power Reactor and Nuclear Fuel development Corporation (PNC) in Japan. This is a liquid-fed joule-heated ceramic melter process for the vitrification of high-level liquid waste (HLLW). Technology developments include a wet type electro-precipitator.

Kitamura et al. (1987) report details of design work scheduled for air cleaning at the HLLW vitrification $p l a n t$ of the Tokai reprocessing $p l$ ant in Japan. The vitrification process includes a ceramic melter with a glass production capacity of $9 \mathrm{~kg} / \mathrm{h}$.

A water-filmed electrostatic precipitator (WEP) is used. A water film continuously cleans the dust-collecting electrode. The gas airflow capacity is $240 \mathrm{~m}^{3} / \mathrm{h}$, the same as for the actual plant. HEPA filters are the final air cleaning device before gas release to the atmosphere. 


\section{ALTERNATIVE AIR CLEANING METHODS REVIEWED}

In addition to air cleaning methods in vitrification plants in Europe and Japan, alternative air cleaning methods of potential interest to HWV are summarized in the following sections. These alternatives begin with those used for high-capacity airflow air cleaning systems in the nuclear industry. The first air cleaning method discussed is the sand filter, which is the current preferred design option for air cleaning at HWVP. The next discussed is the deep-bed glass-fiber (DBGF) filter, developed prior to 1976 (Burchsted et al. 1976) as an a]ternative to sand filters. Next discussed are HEPAs, which are often the standard air cleaning method used in the nuclear industry. Subsequently discussed are remotely-operated modular filter units and highefficiency mist eliminators (HEMES).

Electrostatic precipitators now have limited applications in the nuclear industry, except wet type devices developed in Japan for continuous lowcapacity airflow. Usualiy, electrostatic precipitator systems are not continuous operations, but require downtime for cleaning purposes. Downtime is acceptable for pollution abatement purposes for commercial applications, but not for nuclear industry applications. In contrast, the conventional highvoltage electrostatic precipitator is the predominant industrial, highefficiency, high-cost device for airborne particulate emission control (ACGIH 1988). Electrostatic precipitators are the major air cleaning system for high-airflow-capacity effluents from nonnuclear power plants. No references to the use of electrostatic precipitators for high-capacity airflow cleaning in the nuclear industry were noted in the literature reviewed.

\section{$\underline{\text { SAND FILTERS }}$}

Deep-bed sand filters have graded layers of sand and gravel (Schurr 1986). Some information is available on designing sand filters and optimizing performance. Schurr and Johnston (1975) and Orth et al. (1977) report tests to characterize sand grains and optimize filter performance. A sand filter can be a highly efficient, highly reliable, long-lived filter process desirable for off-gas filtration of radioactive air streams. 
Most information on the filtering efficiency of sand filters is based either on penetration(a) of total particle concentration (i.e., independent of particle size) and measured with photometers for detection equipment or by measurement of the decrease in concentration of radioactive particles(b). At the time of development and installation of existing sand filters, technology for determining particle penetration as a function of particle diameter was limited. Hence, information is limited, or may not exist, for 1) filtration efficiency as a function of particle diameter, and 2) the particle size of maximum penetration. These caveats can be addressed with state-of-the-art particle measuring equipment. Penetration can be determined as a function of particle diameter with instruments such as laser particle counters (LPCS).

\section{Layers in Sand Filters}

Layers of a typical sand filter are shown in Figures 1 and 2 (Burchsted et al. 1976). Air flows upwards from the largest diameter material. A general isometric view and details of a sand filter at the Savannah River Plant is shown in Figure 2 (Burchsted et al. 1976). Note the different specifications for each layer in these two figures.

The graded layers of a sand filter create a continuous-series filtration process where each layer contributes to the system's success. The layer of finest sand must be specified to meet filtration requirements consistent with

(a) Penetration is the passage of particles through a filter or other collector. For a given filter and a given face velocity there is theoretically a particle size for maximum penetration: particles larger or smaller than this may be more efficiently collected. The result of a filter penetration measurement is a function of the particle-size distribution, the filter penetration curve (as a function of particle size) and the photometer response. The instrument or instruments and the test method shall be capable (DOE 1988) of determining within an accuracy and precision of $0.005 \%$ that the number penetration is less than $0.03 \%$ within the size range from $0.1 \mu \mathrm{m}$ to $0.2 \mu \mathrm{m}$.

(b) The basic problem with these test procedures is that the measured filter penetration varies with the number of particles in a given size range and the instrument response function. The primary effect of a widely ranging particle-size distribution is an underestimation of the actual filter penetration (or conversely, an overestimation of the filter efficiency). Filter penetration tests thus represent, at best, an average penetration integrated over the particle-size range. 


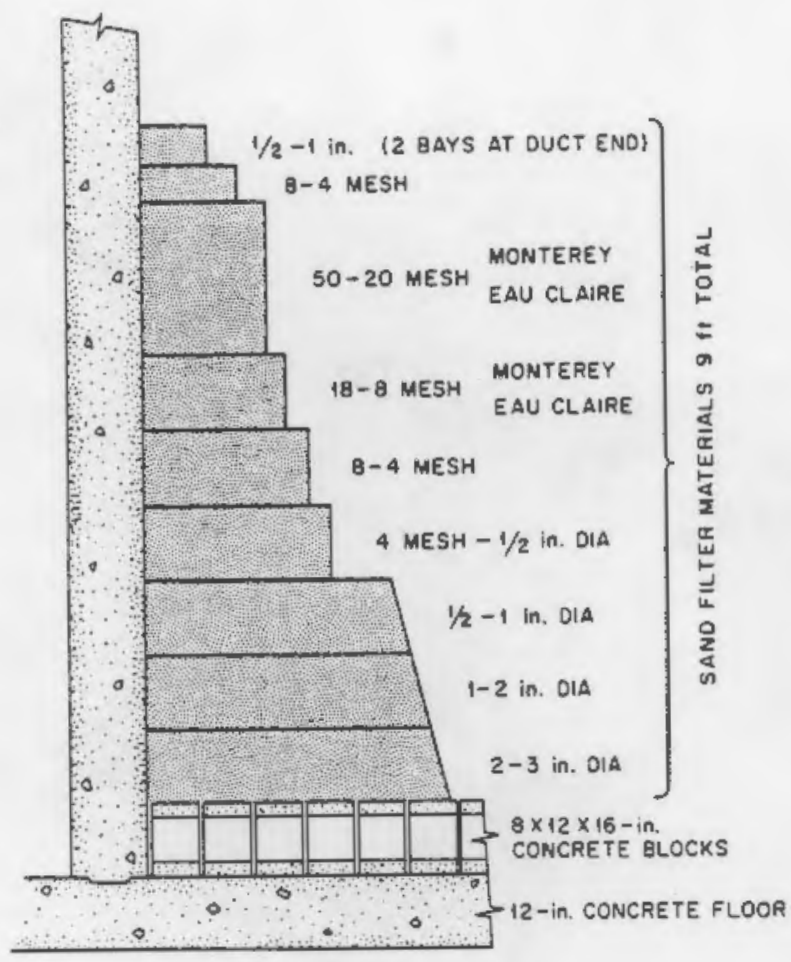

FIGURE 1. Section Through a Typical Sand Fi1ter (From Figure 9.30 Burchsted et al. 1976)

available sands. Burchsted et al. (1976) suggest even small differences among different sands can influence filter performance. They suggest the need for test data to customize specifications to the available sand. Sand filter design must optimize filter performance and vendor capabilities to construct the sand filter.

\section{Advantages/Disadvantages of Sand Filters}

Advantages and observations follow for sand filters, based on results for 84-in.-deep sand filters (Schurr et al. 1973). Sand filters are selfsealing, have particle collection efficiencies that improve with filter lifetime (to the point of breakthrough), and are of proven design. Major attractions of sand filters include large dust-holding capacity, low maintenance requirements, inertness to chemical attack, high heat capacity, fire resistance (if particles collected are noncombustible), and the ability to withstand shock loadings and large changes in air stream pressure without 


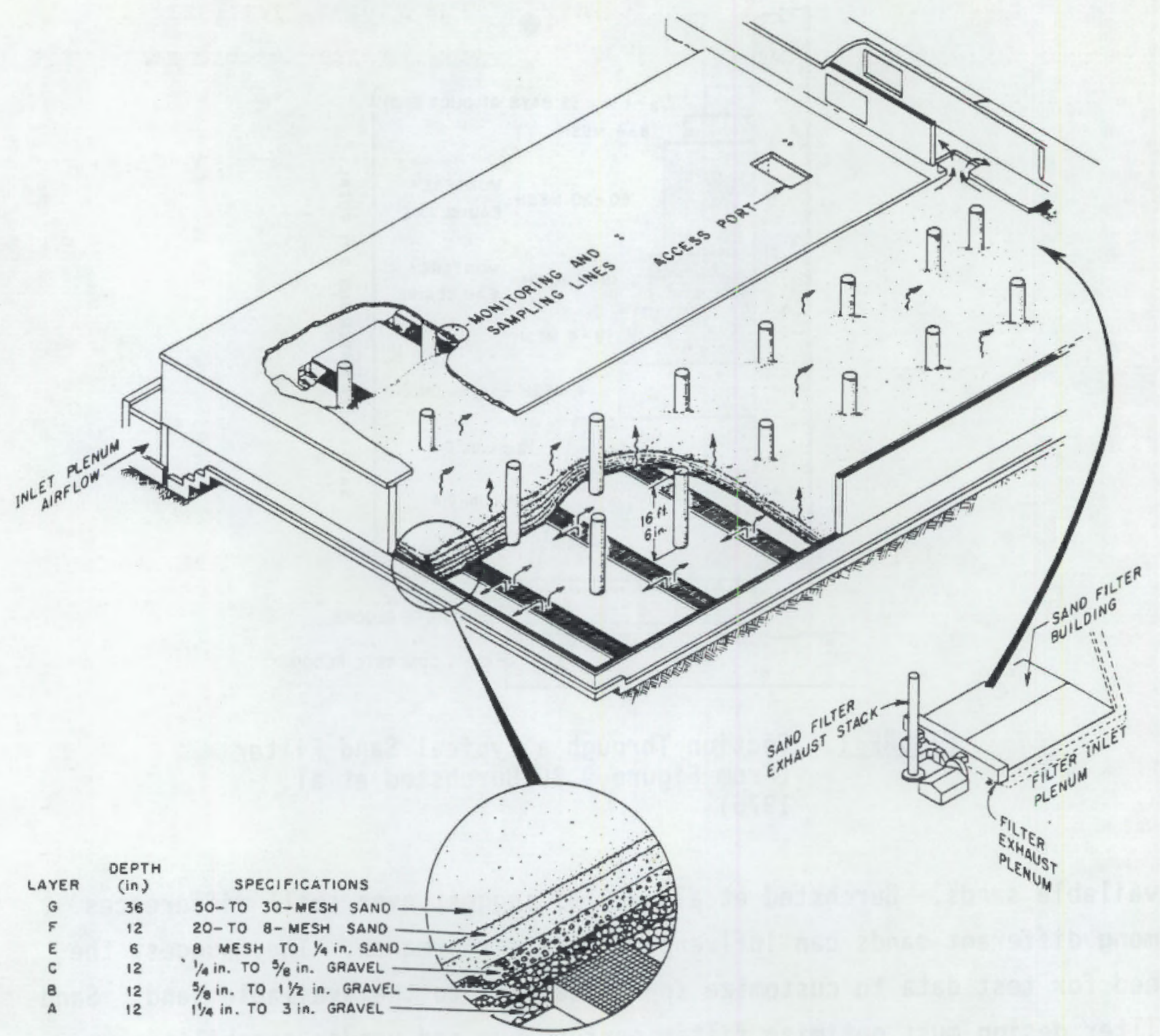

FIGURE 2. General Isometric View and Details of Sand Filter At Savannah River Site (From Figure 9.33 Burchsted et al. 1976)

becoming inoperative (Burchsted et a7. 1976). Removal efficiencies approach that of a single HEPA filter occur if proper sands are used and the contact path is long enough.

Schurr et a1. (1973) also suggest limitations of sand filters. Sand filters have little design flexibility within cost and efficiency limits; they require higher operating pressure than deep-bed glass-fiber filters, require larger filter area, and have a useful lifetime that is more difficult to predict. Disadvantages also include high capital cost; large area; high 
pressure drop and power cost; uncertainties in selection, availability, grading, and handling of suitable sands; and the disposal of the spent unit (Burchsted et a1. 1976).

Sand filters are characteristically one-of-a-kind designs, and are constructed in the field as gravel is positioned and sand is poured in place. Since no standards exist, most information for new designs must come from reports of previous applications.

\section{Installed Sand Filters for Air Cleaning}

Juvinall et al. (1970) report a bibliography and review of sand filters built before 1970. Burchsted et a1. (1976) report installation of the first sand filter at Hanford. Nine others are at Hanford, Savannah River, and the Midwest Fue1 Recovery Plant at Morris, I1linois. All but one are for cleaning ventilation air from fuel reprocessing facilities. There is also a sand filter in the roof of the Zero Power Research Reactor at Idaho Falls, but it is for emergency exhaust cleanup only.

Dimensions and operating data of existing U.S. sand filters are given in Table 2 (Burchsted et al. 1976). Airflow rates for four of these sand filters are greater than the $100,000 \mathrm{ft}^{3} / \mathrm{min}$ HWVP design basis. Two sand $\mathrm{fil}$ ters at the Savannah River Plant have a design flow of $115,000 \mathrm{ft}^{3} / \mathrm{min}$ and two have a design flow of $210,000 \mathrm{ft}^{3} / \mathrm{min}$.

HWVP project personnel requested that this review not address sand filters in greater detail since the HWVP project previously reviewed causes for failure rates in early sand filters (1948 and later) and recent design changes which improve performance. Nevertheless, it must be noted that problems did exist in the early designs of the overall airflow systems (see discussion in Appendix A). Radioactive particles were released to the atmosphere at Hanford because unfiltered air was mixed downstream of air filtered by a sand filter. The sand filter performed satisfactorily.

\section{DEEP-BED GLASS-FIBER FILTERS}

DBGF filters are deep (up to $84-$ in.) beds of compacted fiberglass insulating wool contained in stainless steel boxes (trays) with impervious sides 
TABLE 2. Dimensions and Operating Data of Existing U.S. Sand Filters (Table 9.2 from Burchsted et a1. 1976)

\begin{tabular}{|c|c|c|c|c|c|c|}
\hline $\begin{array}{l}\text { DBS } \\
\text { Filţey } \\
\text { No. } \\
\end{array}$ & $\begin{array}{c}\text { Plan } \\
\text { dimensions(b) } \\
\text { (ft) }\end{array}$ & 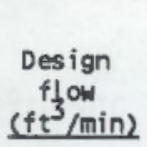 & $\begin{array}{c}\text { Design } \\
\text { Superficial } \\
\text { velocity } \\
\text { (ft/min) } \\
\end{array}$ & $\begin{array}{l}\text { Design } \\
\text { Pressure } \\
\text { drop } \\
\text { (in. } \mathrm{wg}) \\
\end{array}$ & $\begin{array}{c}\text { Date of } \\
\text { initial } \\
\text { operation }\end{array}$ & $\begin{array}{l}\text { Present } \\
\text { status } \\
\text { of DBS }\end{array}$ \\
\hline 1 & $108 \times 46$ & 25,000 & 5.0 & 5.0 & 1948 & Standby \\
\hline 2 & $108 \times 46$ & 25,000 & 5.0 & 7.0 & 1948 & Standby \\
\hline 3 & $96 \times 96$ & 40,000 & 4.3 & 10.0 & 1950 & (c) \\
\hline 4 & $85 \times 85$ & 40,000 & 5.5 & 12.0 & 1951 & Active \\
\hline 5 & $240 \times 100$ & 115,000 & 4.8 & -10.0 & 1954 & Stanchy \\
\hline 6 & $240 \times 100$ & 115,000 & 4.8 & 9.2 & 1955 & Standby \\
\hline & $360 \times 100$ & 210,000 & 5.8 & & 1975 & Active \\
\hline 8 & $360 \times 100$ & 210,000 & 5.8 & & 1976 & Active \\
\hline 9 & $140 \times 103$ & 74,000 & 5.1 & & 1974 & Active \\
\hline 10 & $72 \times 78$ & 32,000 & 5.7 & & 1974 & (d) \\
\hline 11 & 50 to 62.5 (diam) & (e) & (e) & & 1968 & Active \\
\hline
\end{tabular}

(a) Filter identification

1. T Plant. Building 291-T. Hanford West Area. Richland, Washington.

2. B Plant. Building 291-B. Hanford East Area. Richland, Washington.

3. U Plant. Building 291-U. Hanford. Richland, Washington.

4. Redox Facility. Building 291-s. Hanford. Richland, Washington.

5. F Area. Building $294-F$ (old). Savannah River Plant. Aiken, South Carolina.

6. H Area. Building $294-\mathrm{H}$ (old). Savamah River Plant. Aiken, South Carolina.

7. F Area. Building 294-1F (new). Savennah River Plant. Aiken, South Carolina.

8. H Area. Building $294-1 \mathrm{H}$ (new). Savanneh River Plant. Aiken, South Carol ina.

9. SRL. Building 794-A. Savannah River Laboratory. Aiken, South Carolina.

10. Midwest Fuel Recovery Plant (MFRP). Morris, Ill inois.

11. Zero Power Plutonium Reactor Facility. Argonne National Laboratory. Idaho Falls, Idaho.

(b) Inlet side shown first. Outlet side is bold.

(c) Unit in service. Process operation was discontinued in 1975.

(d) MFRP is not engaged in reprocessing, only storage: sand filter is active.

(e) This is an emergency relief system.

and perforated screens at the top and bottom (Burchsted et a1. 1976). For units with greater than $100,000-\mathrm{ft}^{3} /$ min airflow capacity, airflow is usually upward, with filter beds installed horizontally.

The DBGF filter is a large-capacity long-lived filter. A DBGF filter is a prefiltration unit for ventilation and process air in several AEC/ERDA radiochemical and fuel reprocessing operations (Burchsted et al. 1976). A maximum air face-velocity of about $50 \mathrm{ft} / \mathrm{min}$ is desirable in DBGF filters (Burchsted et al. 1976). Airflow capacity is a function of filter size.

Schurr et a1. (1973) tested 84-in.-deep DBGF filters. The total collection efficiency for DBGF filters increased with increasing velocity through the bed, but collection efficiency for smal1 (submicrometer) particles decreased with increasing air velocity. Efficiency decreased 
because the effectiveness of the diffusion mechanism (trapping of submicrometer-sized particles) depends on diffusion.

The satisfactory operation of a DBGF filter is a function of particle collection efficiency, airflow and pressure-drop characteristics, and useful filter lifetime. Operation also depends on maintainability; testability; and details such as tray, joint, and general filter design, flow and service connections, instrumentation, and disposability of spent media.

Early predictions of achievable DBGF filter efficiencies were too optimistic. Eight fiber types gave promise of efficiencies approaching that of a HEPA filter. Only one, the Owens Corning Fiberglas type 115K, was satisfactory under field conditions (Blasewitz et a1. 1951). A permanent curl in this fiber is the key to performance of the 115K fiber. When this fiberglass wool is packed into trays to a packing density from 0.7 to $9 \mathrm{lb} / \mathrm{ft}^{3}$ (11 to $48 \mathrm{~kg} / \mathrm{m}^{3}$ ), the curl resists matting(a). In contrast, straight fibers tend to pack down (matting) under operating conditions, resulting in high pressure drop at even low airflow velocity.

Burchsted et a1. (1976) suggest design considerations for DBGFs. Large DBGF filters should be segmented, with each section contained in an isolatable, individual vault, to provide flexibility for maintenance and testing. Back-flushing is used sometimes to avoid plugging and premature failure or excess resistance, generally necessary only for the first one or two stages of the filter. To simplify disposal of spent filters, the flexibility gained by the ability to replace trays and media may be advantageous. Wet operation is not recommended. If moisture is likely to be present in a DBGF, a stainless steel cladding is recommended for the concrete pit.

A complete sumnary of filter efficiency is beyond the scope of this review. At INEL, Burchsted et a1. (1976) report packing desities of the fiberglass range from 0.7 to $3.01 \mathrm{~b} / \mathrm{ft}^{3}$ (11 to $48 \mathrm{~kg} / \mathrm{m}^{3}$ ) in different filter stages. For the design airflow of $50 \mathrm{fpm}$, the initial (clean filter) pressure drop is about $1.5 \mathrm{in} . \mathrm{wg}$. The final pressure drop, after a total

(a) Burchsted et a1. (1976) list equations to predict the decontamination factor and airflow resistance. These characteristics are functions of bed depth, fiber packing density, and airflow velocity. 
dust loading estimated to be $10,500 \mathrm{lb}$, is $8 \mathrm{in}$. wg. Burchsted et al. (1976) also report the in-place tests of a filter using $0.7 \mu \mathrm{m}$ MMD DOP aerosol. The results indicate an efficiency of about 80 percent, but there was question as to the accuracy of this value because of difficulties in DOP introduction and representative sampling. They indicate the calculated mass efficiency, or arrestance, is $99.95 \%$ (i.e., a mass decontamination factor of 2000). At Hanford, Walser (1980) reports the prefilter was designed for 92.0 percent removal of all particles $0.7 \mu \mathrm{m}$ in diameter or greater.

\section{Advantages/Disadvantages of DBGF Filters}

The DBGF was developed as an alternative to the more costly(a) sand filter (Burchsted et a1. 1976). The DBGF filter employs a medium that has more controllable physical features and more assured availability than filter-grade sands. The DBGF filter permits a larger airflow per unit of volume at lower pressure drop, and has lower operating costs and potentially lower spent-unit disposal cost than a sand filter of equivalent airflow capacity. Schurr et a1. (1973) report DBGF filters have design flexibility to obtain the desired particle collection efficiency. In addition, DBGF filters operate at somewhat low pressure and have a useful lifetime that is more easily predicted than the lifetime for sand filters.

Deep-bed glass-fiber filters also have limitations. They can bypass or leak, can have variable efficiency performance, and are dependent upon quality control in filter media manufacturing. The DBGF filter has a lower particle-collection efficiency than sand filters; has less corrosion resistance, particularly from hydrogen fluoride, and less fire resistance; and lacks the heat-sink and self-repair properties and capability of the sand filter to snub shocks and high-pressure transients (Burchsted et a1. 1976). The design of DBGF filters present a greater challenge than the design of sand filters (Schurr et a1. 1973).

(a) Cost comparisons are based on technology and energy costs prior to 1976. The comparison of relative costs in 1990 is beyond the scope of this literature review. 


\section{Installed DBGF Filters}

DBGF units as large as $150,000 \mathrm{cfm}$ are in building and cell-exhaust installations (Burchsted et a1. 1976). A $126,000 \mathrm{cfm}$ unit is in the canyon exhaust at Hanford ( $B 1$ asewitz 1951), and a 150,000-cfm unit is in the Idaho Chemical Plant at Idaho National Engineering Laboratory.

\section{HIGH-EFFICIENCY PARTICULATE AIR FILTERS}

The "Nuclear Air Cleaning Handbook" by Burchsted et al. (1976) is a significant summary reference for information on the design of HEPA air cleaning systems used by the AEC. Construction details of open-faced HEPA filters are shown in Figure 3 for steel-cased and wood-cased filters (Burchsted et al. 1976). In commercial applications, HEPA filters have been in use in the nuclear power industry since its infancy.

By definition in the nuclear industry, a HEPA filter is a filter that is 99.97\% efficient for $0.3-\mu \mathrm{m}$-diameter particles. RP-CC-001-83-T (IES 1983)

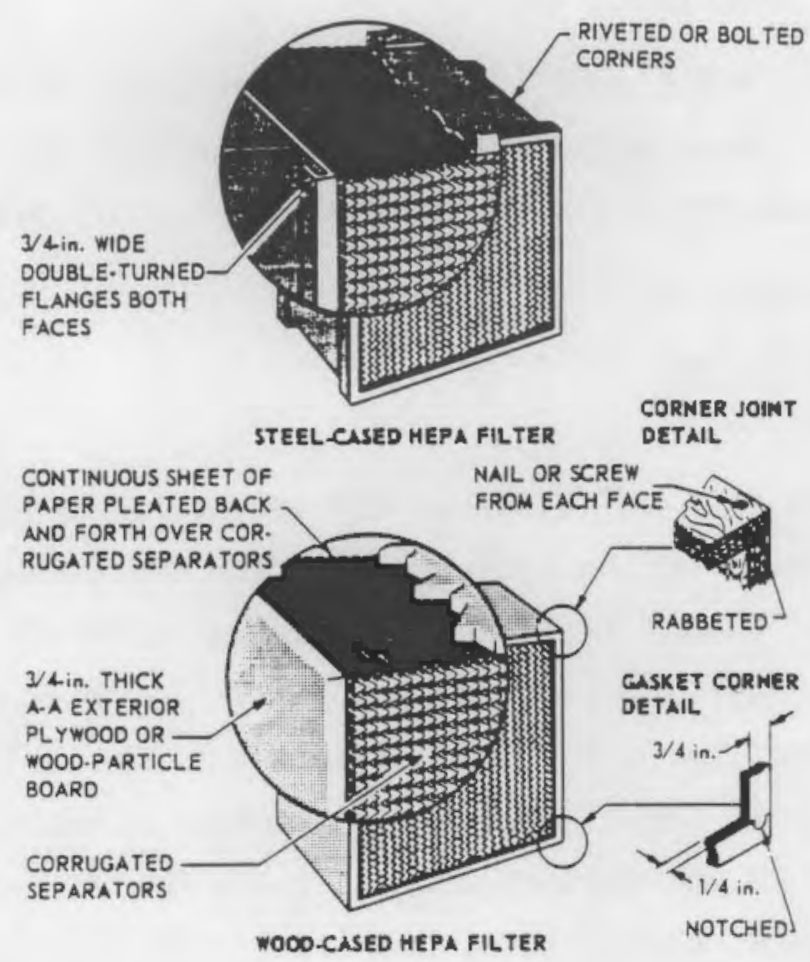

FIGURE 3. Construction Details of Open-Face HEPA Filter (From Figure 3.1 Burchsted et al. 1976) 
states, "HEPA Filter. . . having minimum particle collection efficiency of $99.97 \%$ for 0.3 micron $(\mu \mathrm{m})$ particles, and maximum pressure drop of 1.0 inch water gage $(\mathrm{wg})$." Since HEPA filters have, by definition, a minimum efficiency of $99.97 \%$ for $0.3 \mu \mathrm{m}$, the DF for a HEPA filter is 3333 .

Each filter is tested for airflow resistance and particle retention efficiency during manufacture. The nominal rated airflow capacity of a HEPA filter with frame dimensions of $24 \mathrm{in} . \times 24 \mathrm{in}$. is $1000 \mathrm{ft}^{3} / \mathrm{min}$ at a pressure drop of $1 \mathrm{in}$. water (Burchsted et a1. 1976). Filters tests during manufacture are at $100 \%$ and $20 \%$ of nominal rated capacity per MIL-F-51068 (MILa).

The particle collection efficiency for a filter represents the average efficiency over the cross-sectional area of the filter paper. The filter areas of greater particle penetration are often called "pinhole leaks," and are tolerated if the total penetration across the filter does not exceed $0.03 \%$ ( $99.97 \%$ efficiency). Unless the filter damage occurs during service, filter efficiency increases as the filter accumulates particulate matter during its service 1 ifetime.

The dioctyl phthalate (DOP)(a) used for in-place testing of installed HEPA filter systems has a polydisperse liquid aerosol having an approximate light-scattering mean droplet-size distribution as follows (ANSI-N510):

$99+\%$ less than $3.0 \mu \mathrm{m}$
$50+\%$ less than $0.7 \mu \mathrm{m}$
$10+\%$ less than $0.4 \mu \mathrm{m}$.

ANSI-N510 notes that "the polydisperse DOP aerosol used for in-place leak testing of systems must not be confused with the $0.3 \mu \mathrm{m}$ monodisperse DOP aerosol used for efficiency testing of individual HEPA filters by manufacturers. This latter aerosol is produced by very large equipment that. cannot be used for field testing." Particle sensors for DOP testing have advanced from the "ow1" which is the historical instrument to measure airborne concentrations of DOP, to photometers and state-of-the-art laser particle counters (LPCS). OW1s, photometers, and laser particle counters are

(a) Di-octyl phthalate (DOP, also known as di-ethylhexyl phthalate or DEHP) and di-octyl sebacate (DOS, also known as di-ethyl hexyl sebacate) are currently designated as approved test aerosols (DOE 1988). 
described in Appendix B. The owl indicates total concentration; the LPCs indicate concentration as a function of particle diameter. This caveat about particle size distribution in ANSI-N510 can be avoided by the use of LPCS since individual particle sizes can be determined with LPCs.

Further discussion of HEPA filters is presented in two parts: general overview of HEPAs and HEPA degradation. In-place testing of HEPA filters is discussed in Appendix C.

\section{General Overview of HEPAs}

Jacox (1987) provides a short history of the development and use of HEPA filters as it relates to the engineering of systems that contain HEPA filters. ASHRAE (1988) makes general recommendations for filters installed with central fan systems. One of these recommendations is emphasized for application to the HWVP air cleaning design. Dust connections to and from filters should change size or shape gradually to ensure even air distribution over the entire filter area. Filters should be installed so that the face area is at right angles to the airflow direction. Eddy currents and dead air spaces should be avoided.

There are several specifications for HEPA filters (Flanders 1984). The application of HEPA filters to many air cleaning operations has resulted in several industrial and governmental specifications for HEPA filters. Filters larger than 24 in. $\times 24$ in. $\times 11-1 / 2$ in. should not be used for new nuclear service (Flanders 1988).

Three types of HEPA filters are manufactured with respect to performance. Type 'A' filters are tested for total penetration (i.e., 100-\% efficiency) at rated flow only; Type ' 8 ' filters are tested for total penetration at rated flow and also at $20 \%$ of rated flow, with the filter encapsulated to show casing leaks; and Type ' $C$ ' filters are scanned or tested for leaks across the filter face. HEPA filters for the nuclear industry correspond to Type 'B' designated by Standard RP-CC-001-86 (IES 1986).

Different methods and techniques are used to test filter efficiency at the factory and in the field. The current standard for HEPA filters is, 
"Recommended Tentative Practice of Testing and Certification of HEPA Filters," RP-CC-001-83-T (IES 1983).

\section{HEPA Installation}

The efficiency of HEPA filters can be reduced by damage or installation problems. Damage can occur during handling. Once installed, efficiency loss occurs from leaks in the filter-to-mounting frame seal, or leaks in the mounting frame itself.

HEPA filters must be installed with proper orientation of filter pleats. HEPA installation is with the filter pleats aligned with the vertical axis when airflow is horizontal. This prevents sagging and potential tearing of the medium as the filter becomes loaded during service.

\section{Particle Penetration through HEPA Filters}

Particle penetration through a HEPA filter is a function of both particle size and airflow rate. Particle penetration, or collection efficiency, is principally a function of diffusion and inertial mechanisms within the filter. The effects of these mechanisms on particle collection efficiency are shown schematically in Figure 4 (Burchsted et a1. 1976).

The relative importance of these two mechanisms depends on particle size. The particle size at which neither mechanism dominates is the particle size of maximum penetration, historically cited as a particle diameter of $0.3 \mu \mathrm{m}$. The $0.3 \mu \mathrm{m}$ diameter for maximum particle penetration (minimum efficiency) is only approximate (Cambridge 1989) because spherical particles of

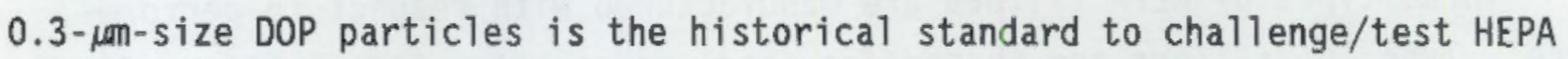
filters. Results of more recent tests with state-of-the-art sampling equipment question the $0.3-\mu m$ theory. There is strong experimental evidence that the actual maximum penetrating particle is $1 / 3$ or $1 / 4$ of the 0.3 -jm-diameter size.

The amount of particle penetration (or particle collection efficiency) is also a function of air velocity through the HEPA filter. Pinhole leaks result in greater penetration at lower-than-rated airflow rate (pressure drop). Particle penetration is greater since the fluid flow resistance through the pinhole is proportional to the square of air velocity through the 

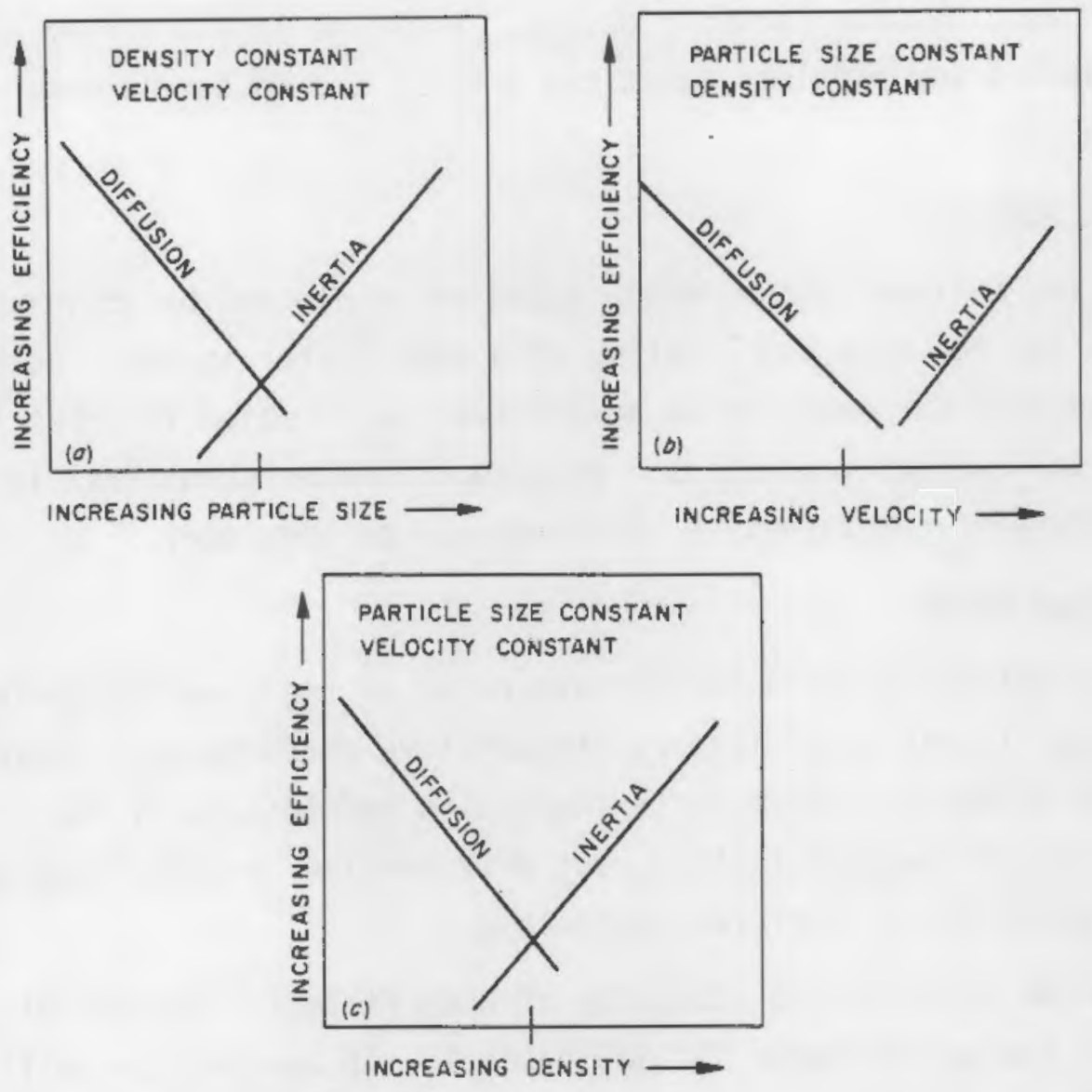

FIGURE 4. General Effects of Principal Mechanisms that Affect Particle Collection Efficiency in HEPA Filters (From Figure 2.17 Burchsted et al. 1976). (a) Effectiveness of Diffusion Mechanism Decreases with Increasing Particle Size; Effecttiveness of Inertial Effects Increases, at a Given Velocity. (b) Effectiveness of Diffusion Decreases with Increasing Velocity; Effectiveness of Inertial Effects Increase, for a Given Particle. (c) For a Given Particle Size and Velocity, Increased Density Decreases Effectiveness of Diffusion and Increases Effectiveness of Inertial Effect.

pinhole. In contrast, the average airflow rate through the filter media is a linear function of air pressure drop. For instance, at $20 \%$ of rated airflow, relative particle penetration through a pinhole leak is approximately 25 times greater than at rated airflow.

Examples of common problems of basic design and operation of HEPA filter systems are described in the following sections. All examples are from operating U.S. light water reactors. Suggestions include possible solutions 
to some basic reasons for poor design. While no single answer exists, understanding why problems exist can greatly aid in development of effective solutions.

\section{HEPA Degradation}

Filter failures can be anticipated and minimized by administrative decision for the expected lifetime of a HEPA filter system. Johnson et al. (1988) suggest the need for an administrative lifetime for HEPA filters used in critical nuclear facilities. Because of unique conditions in each facility, different administrative lifetimes may be necessary.

\section{Filter Aging}

A11 controls on HEPA filters are based on rigid manufacturing standards concerning filtration efficiency, temperature performance, pressure integrity, and strength. Third-party inspection and testing by DOE increases the reliability of new HEPA filters, but only routine in-place testing assures that an aging filter performs adequately.

Age can decrease the integrity of HEPA filters. Johnson et al. (1988) report an evaluation begun in 1980 to decide if age has a significant effect on the structural integrity of HEPA filters. Uncontaminated filters dating back to 1965 were tested. Tensile strength tests on this old medium suggests a decrease in strength. In addition, several of these aged filters were subjected to pressure pulses equivalent to the NRC Region I tornado pulses and shock wave overpressures. Breaking pressure decreased from 25 to $50 \%$. A large increase in complete filter pack blow-out occurred during the simulated NRC Region I tornado tests.

HEPA filter failures and plugging do occur. In addition to leakage through the filter media, failures occur when the aluminum in the filter spacers corrode, for instance by hydrochloric acid.

\section{Survey of HEPA Performance}

A survey of HEPA filter applications and experience at DOE sites provides an overview of the reasons and magnitude of HEPA filter changeouts and failures (Carbaugh 1983). Results suggest that approximately $58 \%$ of the filters surveyed were changed-out in the 3 -year study period, and some $18 \%$ 
were changed-out more than once. Most changeouts (63\%) were due to the existence of a high pressure drop across the filter, which indicated filter plugging/overloading. Other reasons for changeout include leak-test. failure (15\%), preventive maintenance service 1 ife 1 imit (13\%), suspected damage (5\%), and radiation buildup (4\%). Filter failures occur with approximately $12 \%$ of installed filters. Of these failures, most (64\%) occur for unknown or unreported reasons. An additional 19\% of failures occur from handling or installation. Media ruptures, filter-frame failures and seal failures each account for approximately 5 to $6 \%$ of failures.

HEPA filter failure experience also is reported based on DOP leak tests in Belgium operations (Deworm et a1. 1983). This DOP in situ leak-testing of HEPA filtration systems is for nuclear power plants and other nuclear applications in Belgium. A large number $(2,184)$ of air cleaning systems were tested. Thirteen percent of the systems had a penetration greater than $0.05 \%$. The two main causes of leakage are gasket damage $(29 \%)$ and insufficient clamping $(35 \%)$. Sixteen percent of the leakage is from defective filter medium, and the remaining $20 \%$ from different causes. For HEPA filtration systems at nuclear power plants, the main causes of leakage are bypassing (29\%) and defective filter medium (22\%). Leakage through gaskets is less important (13\%).

\section{Dverpressure Failures of HEPAS}

HEPA filters can fail because of overpressure loads. Structural testing was conducted on new HEPA filters by Ruedinger and Wilhe1m (1983a). They show that under favorable conditions of ambient temperature and low relative humidity, commercial filters fail at pressure differential between 4 and about $20 \mathrm{kPa}(\mathrm{a})$. They report break pressures decrease with dust loading, by up to $40 \%$ in break pressure. This decrease is partly attributed to the more easily seen cloud released at the real point of first failure.

Ruedinger and Wilhelm (1983b) suggest new HEPA filters show first failures at differential pressures between $4 \mathrm{kPa}$ and $17 \mathrm{kPa}$ (versus 4 and about $20 \mathrm{kPa}$ in the previous paragraph). They tested both wooden and metal frame

(a) $1 \mathrm{psi}=6.9 \mathrm{kPa}$ 
filters. Higher differential pressures occur before failure with conventionally pleated filter paper packs sealed in a wooden frame with a polyurethane material. Metal frame filters show only poor resistance against overpressures. The weakest point in such filters is the attachment of the filter pack to the metal frame, which limits differential pressures to about $10 \mathrm{kPa}$. With proper attachment, the integrity of the filter pack 1 imits the admissible differential pressure.

HEPA failures also can occur for lower differential pressures. Failures occur for differential pressure between 0.7 and $7.6 \mathrm{kPa}$ (Ricketts et a1. 1987). Test conditions are high air humidity, $50^{\circ} \mathrm{C}$ temperature, and an airflow rate of $1700 \mathrm{~m}^{3} / \mathrm{h}$. The modes and mechanisms of structural failure were determined for wooden-frame deep-pleat filters, the design with the most potential for improvement.

Controlled venting can prevent overpressure damage. Dillmann and Pasler (1983) suggest that controlled venting of containment atmosphere through a properly designed filter system can limit the maximum pressure and prevent containment failure. Experimental data are given to design aerosol filters.

\section{REMOTELY-OPERATED MODULAR FILTER UNITS}

Remotely-operated modular filter housings were developed in West Germany (Jannakos et a1. 1989). Three generations of filter housings were developed; they differ mainly in their remote handling and maintenance ideas. A filter housing of the third generation is shown in Figure 5 (Jannakos et a1. 1987). The vessel is of vertical design. The vessel has connections for gas inlet and outlet and for cleaning the inner housing wall and monitoring the tightness of the filter element seat. The filter element installation in the vessel ensures gas-tight isolation between the upstream and downstream air faces. The filter housing accommodates filter elements capable of retaining wet and dry aerosols(a). The housing may contain HEPA filter elements, packed beds, and filter cartridges arranged in several internal geometries.

(a) Iodine can be removed by $A C 6120$ sorption material used in the annular filter. This material was developed at the Karlsruhe Nuclear Research Center, Kernforschungszentrum Karlsruhe, KfK, West Germany. 


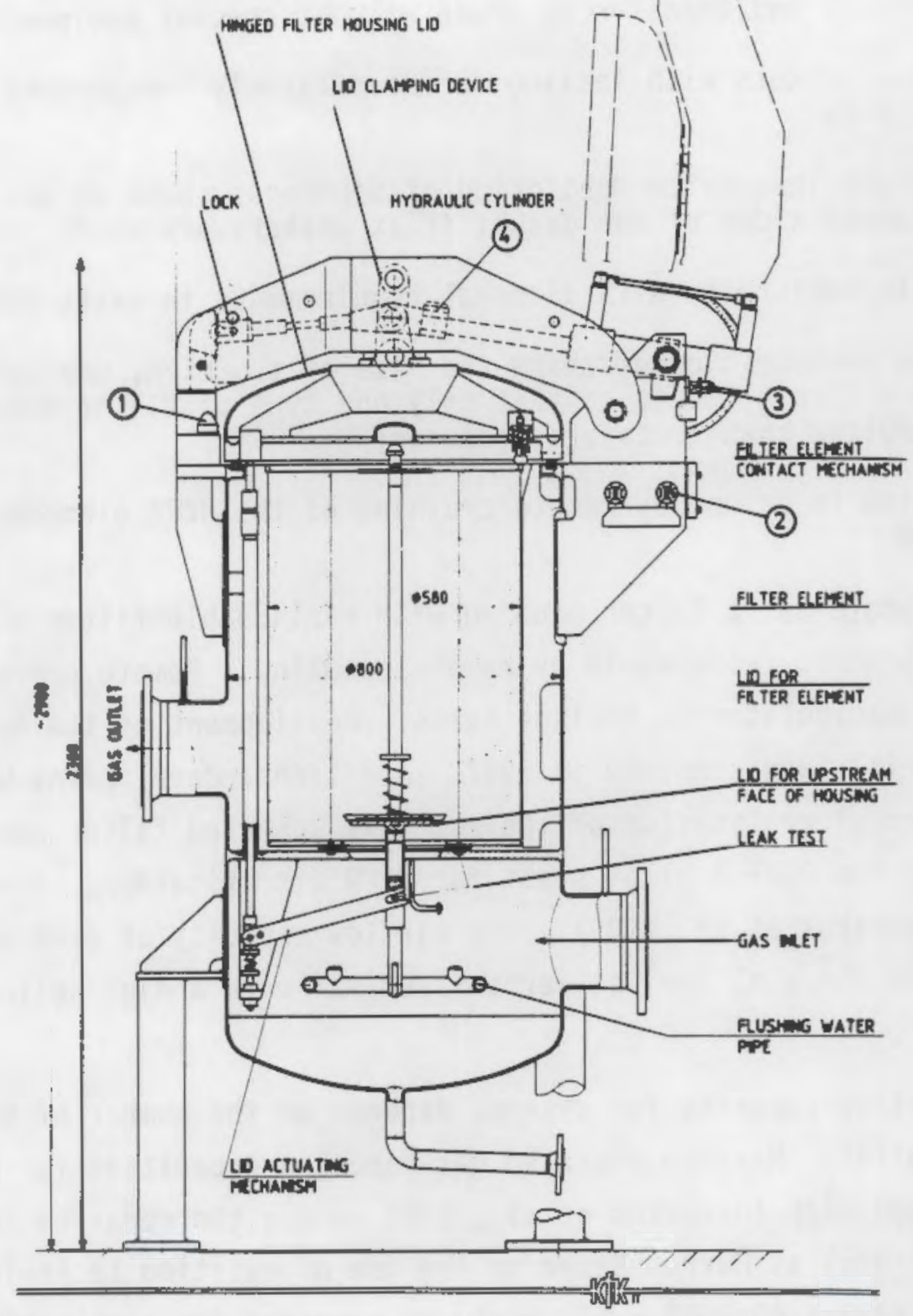

FIGURE 5. Remotely-Operated Filter Housing with HEPA Filter (From Figure 1 Jannakos et al. 1987)

The modules contain removable cylindrical filter elements, which have advantages for remote handling and final disposal. Note, a commercial source for these filter elements is required to ensure continuous operation. Jannakos et al. (1989) suggest that the cylindrical shape offers the following advantages when compared with rectangular filter elements: 
- easy handling in manual and remote operation, i.e., insertion, withdrawal, and transfer by crane without special equipment

- circular gaskets with sealing surfaces largely independent of the filter size

- convenient in-service monitoring of tightness, both on the glued and clamped sides of the gasket (flat gaskets are used)

- shape in conformity with disposal requirements in waste drums

- uniform geometric outer shape and size of the HEPA, demister, and iodine filter elements so that only one type of filter housing and standardized changeouts are necessary

- reduction in volume by remote crushing of the HEPA elements, if desired.

Each module has a filter housing with replaceable filter elements and housing components replaceable by remote handling. Remote operation uses a crane and a manipulator to replace parts. Development of the housing using "cold" materials was complete in 1987. Additional development was complete after successful application of the remotely operated filter housing in hot operation of the PAMELA pilot plant for HLLW vitrification. Five housings are used (Jannakos et a1. 1989). The airflow capacity of each housing is $500 \mathrm{~m}^{3} / \mathrm{h}\left(300 \mathrm{ft}^{3} / \mathrm{min}\right)$ for wet aerosol removal with a high collection efficiency.

The airflow capacity for systems depends on the number of modular units used in parallel. Maximum reported gas-handling capacities for each module are about $3000 \mathrm{~m}^{3} / \mathrm{h}$ (Jannakos et a1. 1987) versus the required $2833 \mathrm{~m}^{3} / \mathrm{min}$ $\left(100,000 \mathrm{ft}^{3} / \mathrm{min}\right)$ at HWVP. Based on the use of existing technology, about 57 modules $(2833 \times 60 / 3000=57)$ would be required for aircleaning at HWV if this maximum airflow were used in each module.

A detailed description of the filter elements (with housings) follows (Jannakos et al. 1987). The polygonal filter element has a filter paper and frame. A supporting tubular structure connects the bottom and top of the frame. The seat gasket is glued to the bottom and fastened by a holding ring. The supporting structure transmits force for tightness from the lid to the bottom gasket. The filter paper is endless, and glued at both ends. The 
filter paper is divided into five filter chambers by $V$-spacers. The inner and outer surfaces of these chambers are of the same width. The filter paper is glued to the $V$-spacers. The lower front faces of the filter paper and the $V$-spacers are embedded in a sealant on the sheet metal bottom and lid. A protective screen is in front of the filter surfaces.

\section{Development of Optimum Internal Geometry of Filter Housings}

Development work on the remotely-operated filter housings produced three generations of filter housings of modular design (Jannakos et al. 1987). Filter elements development progressed from a rectangular design, to a quasi-circular design, to a polygonal filter element for dry aerosol retention (see Figure 6).

Each module has a filter housing with filter elements and housing components replaceable by remote handling. The filter housing contains an array of rectangular filter elements assembled in a quasi-circular filter element. The rectangular filter elements are screwed to a pentagonal stainless steel frame and sealed.

Jannakos et al. (1987) suggest the polygonal filter element is the best choice. Specifications for the filter elements follow. The maximum gas flow is about $3000 \mathrm{~m}^{3} / \mathrm{h}$. The dimensions are $580 \mathrm{~mm}$ in diameter and $900 \mathrm{~mm}$ in height. The filter element weight is about $30 \mathrm{~kg}$.

\section{Air Cleaning Applications}

Remotely-operated filter housings and filter elements were tested for wet and dry aerosol retention (Jannakos et al. 1987) for the Reprocessing and Waste Treatment Project (PWA) development work at the Kernforschungszentrum Karlsruhe (West Germany, KfK). Operating conditions are gas flows up to $3000 \mathrm{~m}^{3} / \mathrm{h}$ and temperatures up to $200^{\circ} \mathrm{C}$. The filter element is replaced by remote handling, and compressed to about one third of its volume to minimize waste volume. The technical development of the filter elements is complete. Testing continues for remote handling, tightness, decontamination factors for various off-gas parameters (humidity, temperature, pressure, $\mathrm{N}_{\mathrm{X}} \mathrm{X}$ ), corrosion, and under accident conditions. 

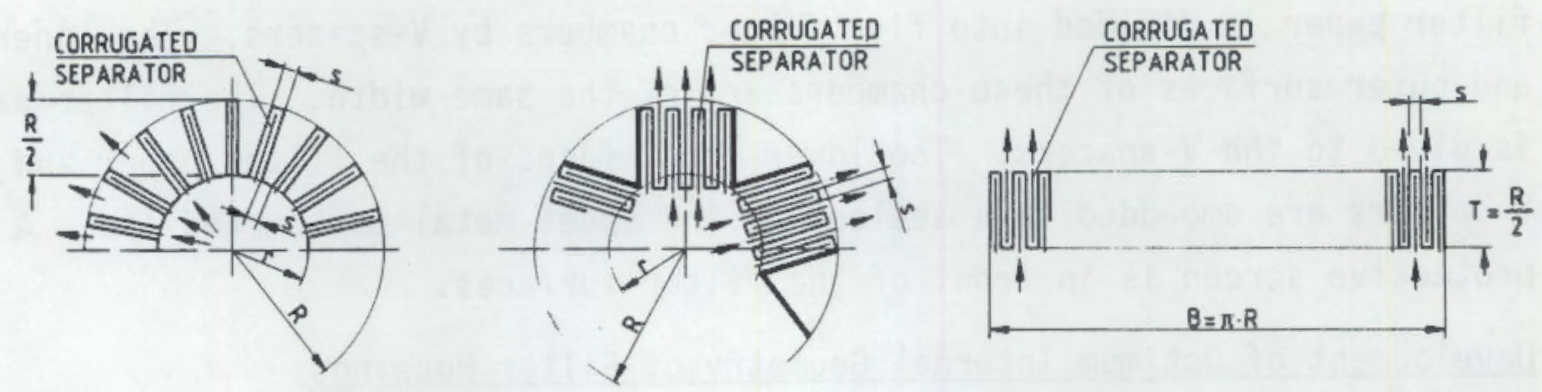

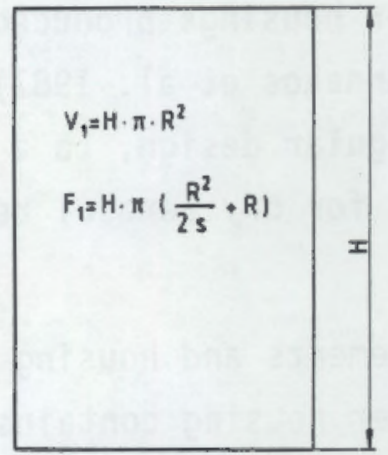

CIRCULAR FILTER

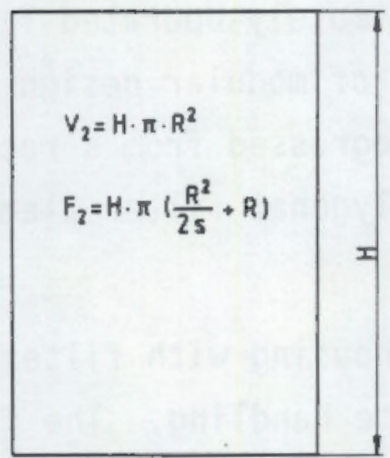

POLYGONAL FILTER

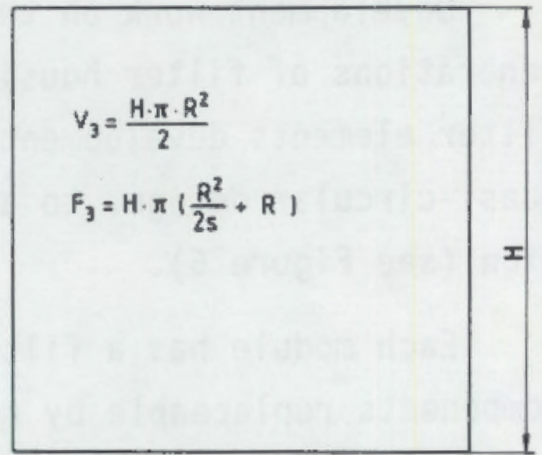

RECTANGULAR FILTER

$$
\begin{aligned}
& P=165 \\
& R=290 \\
& H=820 \\
& F_{1}=F_{2}=F_{3}
\end{aligned}
$$

$$
\begin{aligned}
& \text { FILTER PAPER SURFACE FOR CIRCULAR FILTER } F=H\left[\frac{2 \cdot \pi \cdot r}{5}(R-r)+2 \cdot \pi \cdot r\right) \\
& \text { CONDITION FOR MAX. FLLTER PAPER SURFACE } \frac{d F}{d r}=0 \rightarrow r=\frac{R+5}{2}
\end{aligned}
$$

FIGURE 6. Comparison of Sizes and Arrangement of Filter Papers of Various Filter Elements Considered for Inclusion in Remote Modules (From Figure 9 Jannakos et al. 1987)

\section{PACKED-FIBER MIST ELIMINATORS}

A packed-fiber mist eliminator (PFME) for air cleaning is part of the PASSAT filter system in West Germany (Jannakos et a1. 1989). Remotelyoperated filter elements with fiber glass packing are used. A PFME is shown in Figure 7 (Nagel and Furrer 1985). The design basis is for removal of droplets less than $10 \mu \mathrm{m}$ in diameter. The gas face velocity is limited to about 6 to $8 \mathrm{~cm} / \mathrm{s}$ to get optimum operating conditions of pressure loss and high removal efficiency.

The PFME has a remotely-operated filter housing with a flushing capability for initial removal of droplets and particles, and has remotely- 


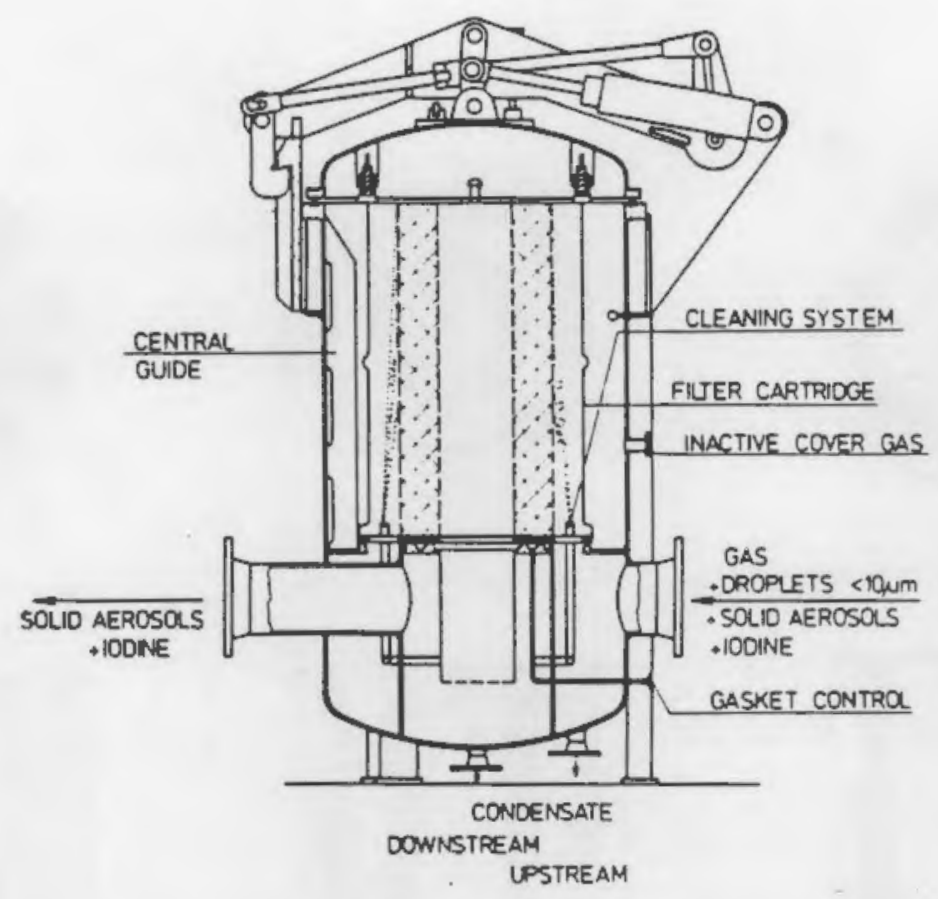

FIGURE 7. PASSAT Packed-Fiber Mist El iminator (PFME) for Droplet Removal for Particle Diameters Less than 10 Micrometers (From Figure 4 Nagel and Furrer 1985)

operated filter components. It operates under simulated dissolver off-gas conditions and extends the service life of HEPA filters.

The PFME is modular in design (Jannakos et a1. 1989). Figure 8 shows a comparison of three geometries considered for filter surfaces. A single-ring layer of fiberglass packing is used to clean radioactive off gases from pilot and test facilities upstream of HEPA filters. The decontamination factor for the single-ring layer filter is $3 \times 10^{3}$. Other geometries considered for packed fiber include a double-ring layer filter and a star-shaped layer filter. Neither of these filter elements was tested.

\section{HIGH-EFFICIENCY MIST ELIMINATORS}

High-efficiency mist el iminators (HEMEs) are used as deep-bed washable filters. As with previous devices for air cleaning for vitrification processes, HEMEs continue to be developed for off-gas control. HEMEs are deepbed regenerable filters being developed as modular units. 

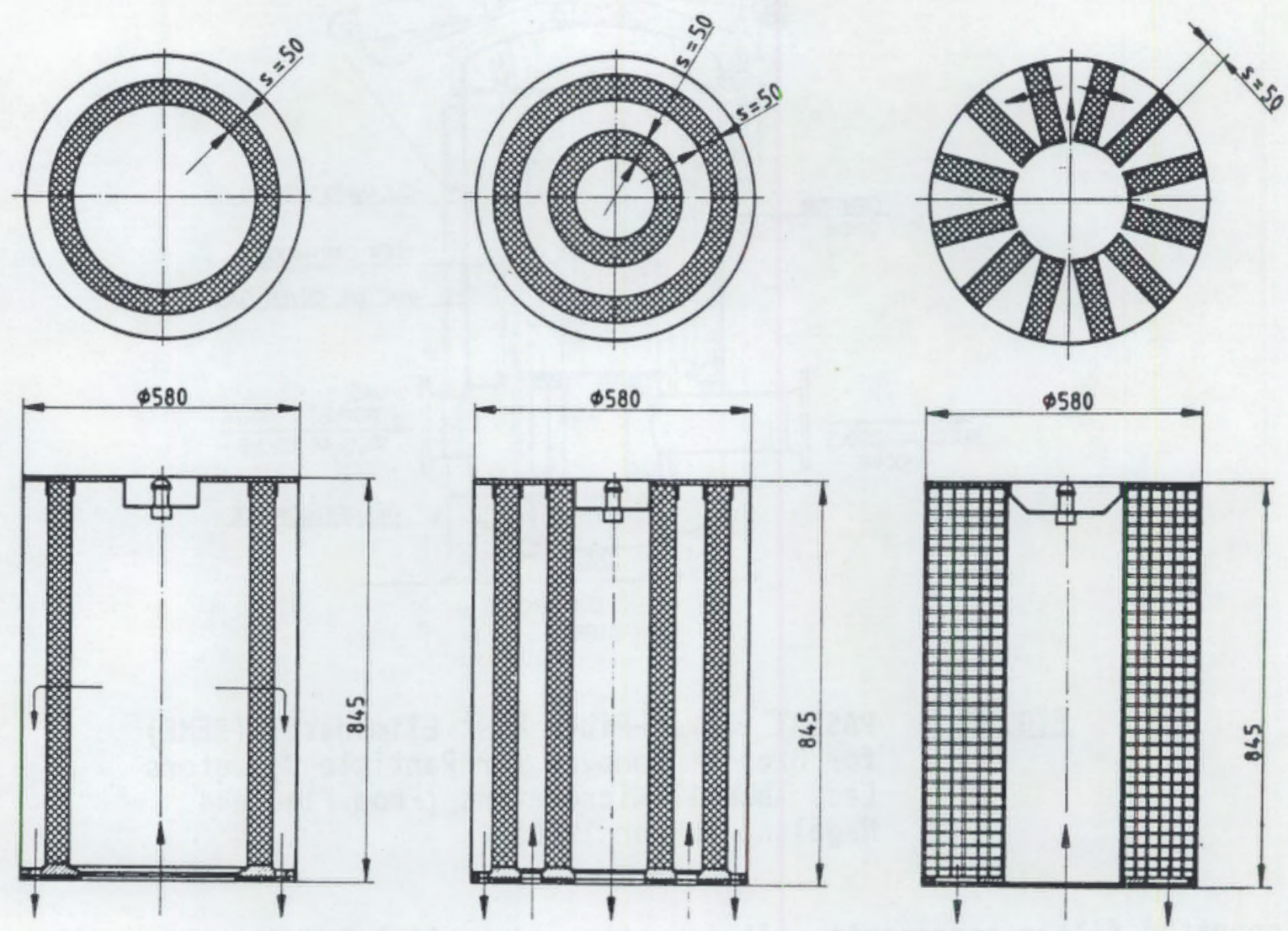

SINGLE ANNULAR FILTER

DOUBLE ANNULAR FIL.TER

$$
\begin{aligned}
& F=0,9 \mathrm{~m}^{2} \\
& F=\text { FILTER SURFACE }
\end{aligned}
$$$$
F=1,57 \mathrm{~m}^{2}
$$

STAR-SHAPED FILTER

$$
F=1,6 \mathrm{~m}^{3}
$$

$$
s=\text { THICKNESS OF FILTER MATERIAL }
$$

FIGURE 8. Packed Fiber Mist Eliminator, Comparison of the Filter Surfaces (From Figure 13 Jannakos et al. 1987)

\section{HEMES at the Savannah River Plant}

A HEME is in the air cleaning system for the Defense Waste Processing Facility (DWPF) at the Savannah River Plant. Details of the system are given by Randall and Sabatino (1987). The DWPF processes liquid waste in a continuous joule-heated ceramic melter. The air cleaning system includes a HEME. A sand filter, which receives all ventilation air from the DWPF, is the final filtering device before off-gas discharge to the atmosphere. 
The HEME has three $0.61-\mathrm{m}-0 \mathrm{D}$ filter elements enclosed in a single vessel. It is a graded filter, a prefilter to remove $30-\mu \mathrm{m}$-diameter particles, followed by a filter to remove $8-\mu \mathrm{m}$-diameter particles (nominal sizes - for particle retention). The filter media in each element are a 1.3-cm-thick glass-fiber blanket (for removal of nominal $30 \mu \mathrm{m}$ particles) followed by a 6.3 -cm-thick glass-fiber blanket (for removal of nominal $8 \mu \mathrm{m}$ particles). Element packing density is $190 \mathrm{~kg} / \mathrm{m}^{3}$.

off-gas flow in the filter elements is from inside to outside of the filter elements. The $30-\mu \mathrm{m}$ blanket serves as a prefilter on the upstream face of the element. The superficial face velocity for the unit is $0.025-\mathrm{m} / \mathrm{s}$, which is low enough so that reentrainment of particles is not a problem. To wash soluble particulates from the element, water sprays continuously into the entering gas at a rate of $18 \mathrm{~g}$ of water per actual cubic meter of off gas.

Gases exiting the HEME pass through a heater and a two-stage HEPA filter. This off gas discharges into the building exhaust tunnel and passes through a sand filter before discharge to the atmosphere. No development testing for HEMEs specific to the DWPF is being done (Randall and Sabatino 1987). The design of these dry filters is established technology, and DWPF design criteria are conservative.

Randall and Sabatino (1987) also report tests for two Monsanto $21.7-\mathrm{cm}$ diameter, F-B series Brink mist-eliminator pads to predict the maximum solids loading $\left(\mathrm{kg} / \mathrm{m}^{3}\right)$. The first has a $7.62-\mathrm{cm}$-thick glass-fiber pad packed to $190 \mathrm{~kg} / \mathrm{m}^{3}$, for removal of nominal $10-\mu \mathrm{m}$ particles. The second is a $1.27-\mathrm{cm}$ blanket of glass fibers (for removal of nominal 30- $\mu \mathrm{m}$ particles) followed by a $6.35-\mathrm{cm}$ pad of glass fibers packed to $220 \mathrm{~kg} / \mathrm{m}^{3}$ (for removal of nominal $8 \mu \mathrm{m}$ particles). (a) This $30-\mu \mathrm{m}$ layer is a prefilter on the upstream side.

(a) The pressure drop across HEMEs can be a disadvantage. Pressure drop is a function of packing density, P. Burchsted et al. (1976) indicate that for the deep-bed fiberglass filter used at Hanford, the airflow resistance is proportional to 1.5 th power of packing density, i.e., p1.5. Higher pressure drop is expected for HEMEs since the packing density range is from 190 to $220 \mathrm{~kg} / \mathrm{m}^{3}$ for these HEMEs. In comparison, the packing density range is from 11 to $48 \mathrm{~kg} / \mathrm{m}^{3}$ for deep-bed fiberglass filters at INEL, reported on p. 22. 


\section{HEME Performance Tests}

High-efficiency mist eliminators are deep-bed regenerable filters used for air cleaning liquid-fed ceramic melter (LFCM) off-gas effluent. Goles and Andersen (1987) report studies to characterize equipment performance, including two low-efficiency quench scrubbers (Scott et al. 1985) and a highefficiency, deep-bed washable filter. Much of the aerosol mass lost to the off-gas system is in the submicrometer particle range. Remote, hardy, highcapacity, efficient scrubbers and filters are necessary to process the large quantity of airborne effluent. High-efficiency mist eliminators, used as deep-bed regenerable filters, were tested. Filter performance is high under dry operating conditions. High face velocities should be avoided if operated wet since condensate and high face velocity can wick (entrain) material through the filter.

\section{Modular Self-Cleaning HEME}

A prototype self-cleaning demister being constructed is shown in Figure 9 (Jannakos et al. 1989). After entering the inlet, gas flows upward, deflects radially outside at the upper end, and flows through the annular gapof the support plate to the filter layers. Gas passes through the filter layers while wet aerosols collect in the filter layers. Gas flows downward between the inner and outer jackets, and exits the filter element through the annular gap between the outer jacket and the sealing ring. The maximum flow rate is $500 \mathrm{~m}^{3} / \mathrm{h}$.

Advantages of this HEME demister include the following:

- The demister has approximately twice the filter surface area of a single filter with the same outer dimensions of the filter element. This means that the filter element has greater airflow capacity.

- A loaded filter element can be cleaned with a liquid spray system, which is an integral part of the filter element. This means that the spray nozzles are replaced during changeout of filter elements. There is less probability for nozzle plugging during the lifetime of the processing plant because of the changeout of filter elements. 


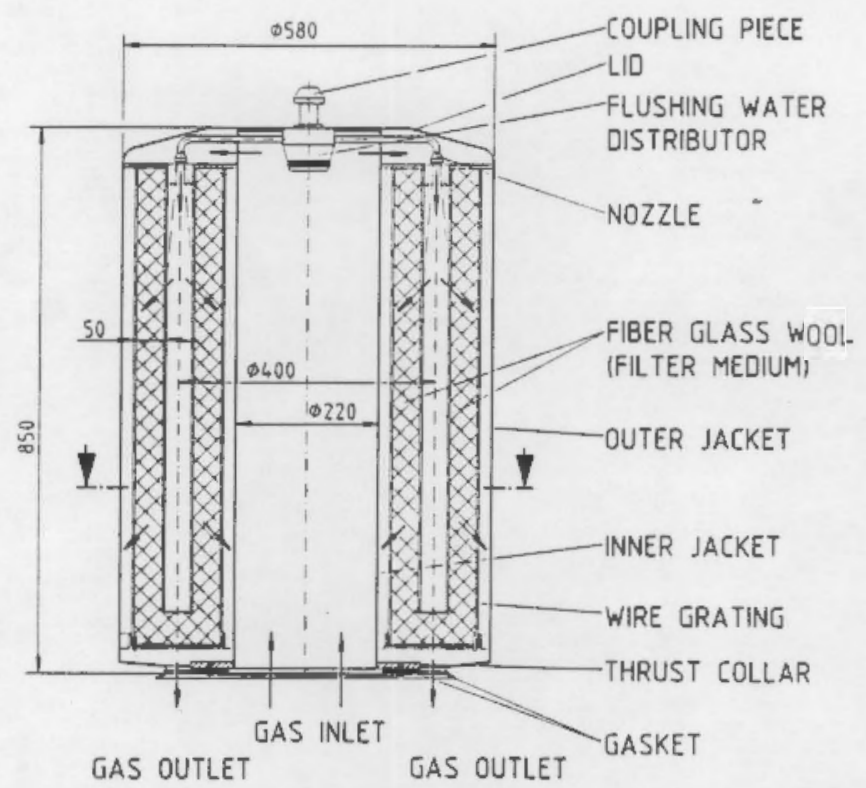

FIGURE 9. Self-Cleaning Demister (from Figure 3 Jannakos et al. 1989) 

CONCLUSIONS

The air cleaning systems that appear feasible for application to HWV include sand filters, HEPA filters, and deep-bed glass-fiber filters. All are high-capacity air cleaning systems. Although deep-bed glass-fiber filters are used at Purex, the fiber glass used is no longer available (Owens Corning Fiberglas type 115K). The original loading of non-crushable fibers in PUREX is still in service for air cleaning. Testing and development is needed for deep-bed glass-fiber filters to be a practical option for HWV; fibers must be found that do not crush and retain their permanent twist, as occurred in the one successful application of fiber glass in packed beds. Remotely-operated modular filter units may be applicable if the use of multiple modules is cost effective. Several modular units are required to obtain the airflow capacity of $2833 \mathrm{~m}^{3} / \mathrm{min}\left(100,000 \mathrm{ft}^{3} / \mathrm{min}\right)$ at HWVP. Although this review identifies the potential for several options for air cleaning at HWVP, the scope of this review does not extend to a recommendation of a preferred air cleaning system for HWVP or to the configuration of equipment into the filter system.

The ultimate measure of air cleaning effectiveness is the reduction in concentration of airborne radioactivity in the effluent release to the atmosphere. To ensure that testing requirements (similar to ANSI-N509) can be met, sufficient permanently-installed tracer injection and sampling ports sha11 be provided to permit accurate testing (similar to ANSI-N510).

Filter testing capabilities must be designed into the air cleaning system selected for HWVP. The design must consider proper location of tracer injection and sample ports. Provisions are required for in-place filterefficiency testing with DOP, or another accepted tracer test technique. The design must emphasize uniformity of tracer concentrations in air and representative sampling techniques for particle concentrations. A uniform tracer concentration is required across the upstream side of the filter face, a satisfactory air-aerosol mixture. Representative samples must be taken both immediately upstream and at a point downstream of the filter, where there is good mixing of filtered air and penetrating tracer or contaninants. 
,

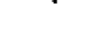




\section{REFERENCES}

ACGIH. 1988. Industrial Ventilation, A Manual of Recommended Practices, 20th Edition. American Conference of Governmental Industrial Hygienists, Committee on Industrial Ventilation, Cincinnati, Ohio.

ANSI-N509. 1980. Nuclear Power Plant Air Cleaning Units and Components. ANSI Standard N509. American National Standards Institute, New York.

ANSI-N510. 1980. Testing of Nuclear Air-Cleaning Systems. ANSI Standard N510. American National Standards Institute, New York.

ASHRAE. 1988. Equipment Handbook. American Society of Heating, Refrigeration and Air Conditioning Engineers (ASHRAE), Atlanta, Georgia.

AWMA. 1981. Control of Particulate Emissions. EPA training manual. Air and Waste Management Association (AWMA), Pittsburgh, Pennsylvania.

AWMA. 1989. The User and Fabric Filtration IV. SP-64, Air \& Waste Management Association (AWMA), Pittsburgh, Pennsylvania.

Blasewitz, A. G., et al. 1951. Filtration of Radioactive Aerosol by Glass Fibers. USAEC Report HW-20847, General Electric Company, Richland, Washington.

Burchsted, C. A. 1981. Index to the 1st through 16th AEC/ERDA/DOE Nuclear air Cleaning Conference. DOE/TIC-11405, National Technical Information Service, Springfield, Virginia.

Burchsted, C. A., A. E. Fuller, and J. E. Kahn. 1976. Nuclear Air Cleaning Handbook. 2nd Ed., ERDA 76-21. Available from National Technical Information Service, Springfield, Virginia.

Calvert, S., and H. M. Englund. 1984. Handbook of Air Pollution Technology, John Wiley and Sons, New York, New York.

Cambridge. 1989. Absolute Filter Testing. Bulletin 12-106. Cambridge Filter Corporation, Syracuse, New York.

Carbaugh, E. H. 1983. "Survey of HEPA Filter Experience." In Proceedings of the 17th DOE Nuclear Air Cleaning Conference. CONF-820833, pp. 790-800. Available from National Technical Information Service, Springfield, Virginia.

Deworm, J. P., W. Slegers and J. B. Pauwels. 1983. "Experience with a Standardized Method and Application of the Recent Trends for In-Situ Testing of HEPA-Filtration Systems." In Proceedings of a Seminar on the Testing and Qperation of Off-Gas Cleaning Systems at Nuclear Facilities Karlsruhe, F.R. Germany 3 May 1982. International Atomic Energy Agency (IAEA) CONF-8205206, pp. 166-177. Available as PC A99/MF AOI from National Technical Information Service, Springfield, Virginia. 
Dillmann, H. G. and H. Pasler. 1983. "Experimental Investigations of Aerosol Filtration with Deep Bed Fiber Filters." In Proceedings of the 17th DOE Nuclear Air Cleaning Conference. CONF-820833, pp. 1160-1174. Available from National Technical Information Service, Springfield, Virginia.

DOE. 1988. Quality Assurance Testing of HEPA Filters. F 3-43, DOE Nuclear Energy Programs, Performance Assurance Office, Oak Ridge National Laboratory, Oak Ridge, Tennessee.

Flanders. 1984. HEPA Filters and Filter Testing, 3rd Edition, Bulletin No. 581D. Flanders Filters, Inc., Washington, North Carolina.

Flanders. 1988. Nuclear Grade HEPA Filters, Butlet in No. 821E. Flanders Filters, Inc., Washington, North Carolina.

Furrer, J., A. Linek, and R. Kaempffer. 1983. "Dissolver Off-Gas Cleaning in Reprocessing Plants: Testing and Operation of Mist Eliminators, HEPA and Iodine Filters." In Proceedings of a Seminar on the Testing and Operation of Off-Gas Cleaning Systems at Nuclear Facilities Karlsruhe, F. R. Germany 3 May 1982. International Atomic Energy Agency (IAEA) CONF-8205206, pp. 592-618. Available as PC A99/MF A01 from National Technical Information Service, Springfield, Virginia.

Goles, R. W. and C. M. Andersen. 1987. "LFCM Emission and Off-Gas System Performance for Feed Component Cesium." In Spectrum'86 - Proceedings of the American Nuclear Society International Topical Meeting on Waste Management and Decontamination and Decommissioning. CONF-860905, pp. 1068-1084, American Nuclear Society, La Grange Park, Illinois.

Griem, M. C. 1988. "Ionizing Wet Scrubbers, Removal of Submicron Particulates at High Level of Energy Efficiency." VIP-Il, p. 903-915. Proceedings of the Third International Conference on Electrostatic Precipitation. Available from Air \& Waste Management Association (formerly APCA), Pittsburgh, Pennsylvania.

Hall, H. J. 1988. "Critical Electrostatic Precipitator Technology: Factors for Very Fine Particle Collection." VIP-11, pp. 763-782. In Proceedings of the Third International Conference on Electrostatic Precipitation. Available from Air \& Waste Management Association (formerly APCA), Pittsburgh, Pennsylvania.

IES. 1983. Recommended Tentative Practice of Testing and Certification of HEPA Filters, Standard RP-CC-001-83-T. Institute of Environmental Sciences (IES), Mt. Prospect, Illinois.

IES. 1986. Standard RP-CC-001-86. Institute of Environmental Sciences, Mt. Prospect, Illinois.

Jacox, J. W. 1987. "HEPA Filters in Nuclear Power P1 ants." ASHRAE Irans. $92(2): 891-897$. 
Jannakos, K., H. J. Becka, G. Potgeter, and J. Furrer. 1987. "Development at the Karlsruhe Nuclear Research Center of Remotely Operated Filter Housings and Filter Elements for Reprocessing Plants." In Proceedings of the 19th DOE/NRC Nuclear Air Cleaning Conference. CONF-860820, pp. 426-441. Available from National Technical Information Service, Springfield, Virginia.

Jannakos, K., G. Potgeter, M. Mock, and J. Furrer. 1989. "Advanced Filters for Nuclear Facilities and Filter Conditioning for Disposal." In Proceedings of the 20th DOE/NRC Nuclear Air Cleaning Conference. NUREG/CP-0098, CONF 880822, pp. 1055-1063. Availabie from National Technical Information Service, Springfield, Virginia.

Jennings, S. D. 1989. Proceedings of the 20th DOE/NRC Nuclear Air Cleaning Conference: An Index to the 1st Through 20th AEC/ERDA/DOE and DOE/NRC Nuclear Air Cleaning Conferences. NUREG/CP-0098, CONF-880822. Available from National Technical Information Service, Springfield, Virginia.

Johnson, J. S., D. G. Beason, P. R. Smith, and W. S. Gregory. 1988. "The Effect of Age on the Structural Integrity of HEPA Filters." In Proceedings of the 20th DOE/NRC Nuclear Air Cleaning Conference. NUREG/CP-0098, CONF880815, pp. 366-382. Available National Technical Information Service, Springfield, Virginia.

Juvinal1, R. A., R. W. Kessie and M. J. Stindler. 1970. Sand-bed Filtration of Aerosols: A Review of Published Information on Their Use in Industrial and Atomic Energy Facilities. ANL-7683, Argonne National Laboratory, Argonne, Illinois.

Kitamura, M., M. Hatta, R. Tatsugae, T. Takeda, M. Hagiwara, N. Sasaki, H. Kashihara, and M. Yamamoto. 1987. "Development of HLLW Vitrification offGas Treatment Process in Japan." In Spectrum '86-Proceedings of the American Nuclear Socjety Internationa 7 Topical Meeting on Waste Management and Decontamination and Decommissioning. CONF-860905, pp. 1028-1037, American Nuclear Society, La Grange Park, Illinois.

Martin, A. E. 1981. Emission Control Technology for Industrial Boilers. Noyes Data Corporation, Park Ridge, New Jersey

McIlvaine, R. W. 1989. "Fabric Filter Trends." SP-64, pp. 4-18. In Proceedings of The User and Fabric Filtration Equipment IV, APCA International Specialty Conference Proceedings. Available Air \& Waste Management Association (formerly APCA), Pittsburgh, Pennsylvania.

MIL(a). Military Specification Filter, Particulate, High Efficiency, Fire Resistant. MIL-F-51068.

Moore, E. B. 1984. Control Technology for Radioactive Emissions to the Atmosphere at U.W. Department of Energy Facilities. PNL-4621, Pacific Northwest Laboratory, Richland, Washington. 
Nage1, K., and J. Furrer. 1985. "Calculating Released Amounts of Aerosols." In Proceedings of the 18th DOE Nuclear Air Cleaning Conference. CONF-840806, pp. 873-894. Available from Nationa] Technical Information Service, Springfield, Virginia.

Ogawa, A. 1984. Separation of Particles from Air and Gases. Volumes I and II. CRC Press, Inc., Boca Raton, Florida.

Orth, D. A., G. H. Sykes and G. A. Schurr. 1977. "The SRP Sand Filter: More Than a Pile of Sand." In Proceedings of the 14th DOE Nuclear Air Cleaning Conference. CONF-760822, pp. 542-556. Available from National Technical Information Service, Springfield, Virginia.

Randa11, C. T., and D. M. Sabatino. 1987. "Dff-Gas System for the Savannah River Plant Defense Waste Processing Facility." In Spectrum'86 - Proceedings of the American Nuclear Society International Topical Meeting on Waste Management and Decontamination and Decommissioning. CONF-860905, pp. 1013-1027, American Nuclear Society, La Grange Park, Illinois.

REA. 1980. Modern Pollution Control Technology, Vol. 1, Air Pollution Control. Staff of Research and Education Association, Research and Education Association, New York, New York.

Rea, M., ed. 1988. Proceedings of the Third International Conference on Electrostatic Precipitation. Available Air and Waste Management Association (formerly APCA), VIP-11, Pittsburgh, Pennsylvania.

Ricketts, C. I., V. Ruedinger, and J. G. WiThelm. 1987. "High Efficiency Particulate Air Filter Behavior under High Humidity Airflows." In Proceedings of the 19th DOE/NRC Nuclear Air Cleaning Conference. CONF-860820, pp. 319-352. Available from National Technical Information Service, Springfield, Virginia.

Ruedinger, V., and J. G. Wilhelm. 1983a. HEPA Filter Response to High Air Flow Velocities. In Proceedings of the 17th DOE Nuclear Air Cleaning Conference. CONF-820833, pp. 1069-1092. Available from National Technical Information Service, Springfield, Virginia.

Ruedinger, V. and J. G. Wilhelm. 1983b. "Testing HEPA Filter Response to High Flow Velocity and 0verpressure." In Proceedings of a Seminar on the Testing and Operation of Off-Gas Cleaning Systems at Nuclear Facilities Karlsruhe, F.R. Germany 3 May 1982. International Atomic Energy Agency (IAEA) CONF-8205206, pp. 101-117. Available as PC A99/MF A01 from National Technical Information Service, Springfield, Virginia.

Sasaki, N., S. Torata, H. Igarashi, H. Kshihara and M. Yamamto. 1987. "Advances in Vitrification Techniques in Japan." In Spectrum' 86 - Proceedings of the American Nuclear Society International Topical Meeting on Waste Management and Decontamination and Decommissioning. CONF-860905, pp. 737-745, American Nuclear Society, La Grange Park, Illinois. 
Schurr, G. A. 1986. "Sand Specification for the Deep-Bed Sand Filter." ASHRAE Trans, 92(1B):706-715.

Schurr, G. A. and J. E. Johnston. 1975. "Characterizing Sand Grains to Opt imize Filter Performance." In Proceedings of the 13th DOE Nuclear Air Cleaning Conference. CONF-740807, pp. 1039-1046. Available from National Technical Information Service, Springfield, Virginia.

Schurr, G. A., D. B. Sippler, and D. C. Guyton. 1973. "Deep-Bed Filter Performance Tests." In Proceedings of the 12th AEC Nuclear Air Cleaning Conference. CONF-720823, pp. 596-618. Available from National Technical Information Service, Springfield, Virginia.

Scott, P. A., R. W. Goles, and R. D. Peters. 1985. Technology of Off-Gas Treatment for Liquid-Fed Ceramic Melters. PNL-5446, Pacific Northwest Laboratory, Richland, Washington.

Walser, R. L. 1980. Purex Filter Safety Analysis Study. RH0-CD-904, Rockwell Hanford Operations, Richland, Washington.

Wiese, H., G. Hohlein, and S. Weisenburger. 1987. "Vitrification of SodiumRich High-Level Waste." In Spectrum '86. - Proceedings of the American Nuclear Society International Topical Meeting on Waste Management and Decontamination and Decommissioning. CONF-860905, pp. 851-860, American Nuclear Society, La Grange Park, I11 inois. 

APPENDIX A

MISINTERPRETATION OF EARLY SAND FILTER PERFORMANCE 
APPENDIX A

\section{MISINTERPRETATION OF EARLY SAND FILTER PERFORMANCE}

Problems did exist in the early designs of the overall airflow systems for sand filters at Hanford. This appendix discuses 1) a 1989 Senate report (Alvarez, R. 1989) that indicates early leakage problems for these sand filters (which must be discussed for completeness of this review), and 2) scientific literature, which suggests that problems existed in other parts of the airflow system. The sand filters were efficient. Particles were released to the atmosphere because unfiltered air was mixed downstream of air filtered by a sand filter (Juvinall et al. 1970).

\section{INFERENCE FROM 1989 REPORT}

Questions about the early performance of sand filters at Hanford were recently raised in a report by the Senate Governmental Affairs Committee in December 1989 (Alvarez, R. 1989). This report address severat serious and little known public health problems encountered during the early years of the U.S. nuclear weapons program (1945-1954). The report refers to comments on sand filter leakage by the (AEC's) Advisory Committee for Biology and Medicine (ACBM). The report (AEC/ACBM 1948) is quoted (p. 11):

According to notes of a meeting of the ACBM held on January 12 , 1951, a Hanford official stated: 'At the time [October, 1948] our principal concern was with the radioactive particle problem. Sand filters were then in operation but numerous fine particles in the dissolver off gasses were bypassing these filters. This condition has only recently been corrected by the installation of glass fibre filter. Active iodine is not removed from the stack gases chemically. The particle problem still remains in my opinion a very serious health problem. This problem is present in other A.E.C. manufacturing plants and will be important in new installations not only from the standpoint of real injury but because of the extreme difficulty of defense in cases of litigation.' 
Documentation is inciuded here to 1) acknowledge the existence of the Senate report (and newspaper articles which refer to the Senate report) and 2) document that the assumed leakage was caused by the introduction of unfiltered air downstream of air filtered by a sand filter (Juvinall et al. 1970). The source of particles emitted to the atmosphere was from the unfiltered air, not from air filtered through the sand filter.

\section{EARLY SCIENTIFIC LITERATURE ON INFERRED LEAKAGE}

The following synopsis documents reports that indicate unfiltered air was introduced downstream of the sand filter (i.e., termed bypassing in the Senate report). This synopsis of the early history of Hanford operations is relevant to sand filters and atmospheric releases from stacks (Juvinall et a1. 1970).

Activity discharged from the $200-\mathrm{ft}$ stack (200 Area) was thought to be adequately dispersed by dilution until late in 1947 (Juvinall et al. 1970). At that time, "hot specks" were found on the ground around the stack area. To determine the source of these particles, samples of the airstream were collected upstream of the fans, downstream from the fans at the stack base, $50 \mathrm{ft}$ up the stack, and at the dissolver off-gas lines entering the stack breaching.

Samples of the airstream contained many particles that were magnetic and high in iron concentration, resembling rust from ventilation ductwork (Juvinall et al. 1970). The deteriorated black iron ductwork was replaced with stainless steel. This eliminated large particles, but not the small active particles or spray or dust from the processing solutions.

Sand beds were designed to treat the air. Zahn (1953) indicates sand filters installed in 1948 essentially eliminated the contamination problem and performed satisfactorily. However, early data indicated that the stack gases were recontaminated, i.e., the bypassing problem in the Senate report.

Lapple (1949) suggests that recontamination of the air cleaned by the sand filter can be due to the following:

1) recontamination due to previous accumulations on the stack 
2) by-passing the sand filer

3) contamination from the dissolver off-gases which are bled into the base of the stack.

Juvinall et al. (1970) indicate the small-particle problem seemed to be that dissolver off gases were not passed through the sand filter, but were mixed with sand filter effluent gases at the base of the stack.

Reports that indicate dissolver off gases were not passed through the sand filter include the following:

- Lapple (1949) suggests that a great part of the recontamination originates from the dissolver off-gases (i.e., dissolver off-gas lines entering the stack breaching). One method considered for eliminating the discharge was "the dissolver off-gasses could be discharged directly into the existing large sand filter."

- Work (1948) indicates, "the apparent recontamination of the air between the point of exit from the sand $\mathrm{fi}$ ter and the $50 \mathrm{ft}$ sampling point in the stack."

- Roberts (1958) indicates, "A7though the large, and more serious, particles were eliminated by the equipment replacements, numerous smaller particles continued to be emitted. This condition was successfully overcome by installing and diverting the stack effluent through a sand filter prior to discharging to the atmosphere."

\section{REFERENCES}

AEC/ACBM. 1948. Atomic Energy Commission, Advisory Committed for Biology and Medicine, Minutes of the Twelfth Meeting, Richland, Washington, October 8-9, 1948. U.S.A.E.C. Archives, Germantown, Maryland.

ATvarez, R. 1989. Early Health Problems of the U.S. Nuclear Weapons Industry and Their Implications for Today, S. Prt. 101-63, Committee Print, 101st Congress, 1st Session, Report of the Majority Staff of the Committee on Governmental Affairs, United States Senate, U.S. Government Printing Office, Washington, D.C.

Juvinal1, R. A., R. W. Kessie, and M. J. Stindler. 1970. Sand-bed Filtration of Aerosols: A Review of Published Information on Their Use in Industrial and Atomic Energy Facilities. ANL-7683, Argonne National Laboratory, Argonne, Illinois.

Lapple, C. E. 1949. 200 Area-Dissolver Off-Gases. HDC-969 (declassified), January 18, 1949. General Electric Co., Hanford Works, Richland, Washington. 
Parker, H. M. 1948. Review of the Stack Discharge Active Particle Contamination Problem. HW-9259 (declassified), Health Instruments Department, General Electric Co., Hanford Works, Richland, Washington.

Roberts, R. E. 1959. History of Airborne Contamination and Control - 200 Areas. HW-55569RD (declassified). General Electric Co., Hanford Works, Richland, Washington.

Work, J. B. 1948. Decontamination of Separation Plant Ventilation Air. HW-11529 (declassified). General Electric Co., Hanford Works, Richland, Washington.

Zahn, L. L., Jr. 1953. Comparative Study of Alternative Fibrous Glass and Sand Exhaust Ventilation Air Filter Installations for Purex. HW-30142

(declassified). General Electric Co., Hanford Works, Richland, Washington. 
APPENDIX B

PARTICLE INSTRUMENTATION FOR IN-PLACE TESTING 
APPENDIX B

\section{PARTICLE INSTRUMENTATION FOR IN-PLACE TESTING}

The owl and photometer are instruments for measuring airborne concentration of particles. They are used to determine filtering efficiency by measuring concentrations upstream and downstream of filters. A brief description of each instrument follows.

OWL

The owl is a forward-scattering photometer historically intended for filter testing for $0.3-\mu \mathrm{m}$-diameter DOP particles. The owl indicates particle size by measuring the ratio of scattered light at two polarizations.

The owl is an instrument for determining the equivalent polarization ratio diameter of an aerosol by viewing two fields of polarized light scattered from the aerosol particles and adjusting the instrument until the field intensities are apparently equal. The polarization ratio, or angle measured from the instrument, is directly related to the average size of submicrometer aerosol having a geometric standard deviation (GSD) no greater than 1.40 (DOE 1988). In the optical ow1, the fields are viewed ocularly, and the instrument is adjusted manually. In the photo electric ow the polarization ratio is indicated by the balancing of signals from two electronically balanced photo multiplier tubes which view the field.

\section{PHOTOMETER}

A brief description of a photometer follows. A photometer is an instrument with a linear read-out and near-forward light scattering. Lenses focus light from a filament source upon the scattering volume. A baffle on the focusing lens excludes direct transmission of the source and forms a cone of light. Another lens focuses forward scattered light from the particles 
onto a photomultiplier tube. The basic readout of the instrument is in percent penetration, using the unfiltered aerosol as the span calibration point.

A single-particle, particle-size spectrometer is an aerosol particle detector that isolates a sufficiently small volume of particle-laden air to size single particles suspended in the sample. It accumulates the signals produced by individual particles in the sample in separate storage registers to provide a quantitative print-out and/or display of particle number size distribution over a measured sample volume (DOE 1988).

Improved particle size discrimination can be obtained with laser particle counters. A single-particle, light-scattering photometer (SPLSP) is a filter penetration measuring device which employs a single-particle, lightscattering particle sizing spectrophotometer capable of recognizing, differentiating, and recording particle sizes and size distributions in not fewer than 16 contiguous size fractions between approximately 0.1 to $1.0 \mu \mathrm{m}$, and is capable of displaying the same (DOE 1988). These devices are often called laser particle counters.

\section{REFERENCE}

DOE. 1988. Quality Assurance Testing of HEPA Filters. F 3-43, DOE Nuclear Energy Programs, Performance Assurance Office, Oak Ridge National Laboratory, Oak Ridge, Tennessee. 


\section{APPENDIX C}

IN-PLACE TESTING OF FILTERS 
APPENDIX C

\section{IN-PLACE TESTING OF FILTERS}

Provisions for in-place filter-efficiency testing with dioctyl phthalate (DOP) or other accepted test technique should be built into the filter system. Particular attention must address 1) the ability to get a satisfactory air-aerosol mixture (uniform concentration across the filter face) entering the filters and 2) the ability to take reliable samples immediately upstream and at a point downstream, where there is good mixing of the filtered air and penetrating contaminants.

An air-aerosol mixing uniformity test is prerequisite to in-place leak tests for high-efficiency particulate air (HEPA) filter banks (ANSI-N510 $1980)^{(a)}$. The purpose of the test is to verify that tracer injection and sampling ports are located to provide proper mixing of the tracer in the air approaching the HEPA filter bank to be tested, or in the sample plane to be tested downstream of the bank. This test is conducted only upon completion of initial system installation, modification, or major repair, and is not required each time an in-place test of the filter is made. A valid in-place test is not possible without a uniform tracer-air mixture.

The in-place test is used during acceptance testing of the air cleaning system, after any filter replacement, or after any maintenance activity in the filter housing to verify that 1) filters are not damaged, 2) filters are installed properiy, 3) there are no leaks in the mounting frame or between the mounting frame and the housing, and 4) the system contains no bypassing (for example, through defective or inefficient bypass dampers, through adjacent plenums, or through penetrations, such as electrical conduits, that penetrate the mounting frame). Bypassing compromises the function of the filters. This test is also conducted periodically in both operating and

(a) DOE-RL Order 5480.4 1ists ANSI-N510 as a mandatory standard for nuclear facility safety. Paragraph 9 of this standard specifies an air-aerosol mixing uniformity test; valid in-place testing is not possible without this test. 
standby systems to check on possible degradation of the filters or the filter installation (for example, development of cracks in the mounting frame or mounting-frame-to-housing seal).

In-place testing ensures that aging HEPA filter systems perform adequately. Several references for HEPA specifications and tests are summarized by Cambridge (1989). ANSI-N10I.I addresses testing of filters and filter banks for overall efficiency for particle penetration. Fitter efficiency is historically established using a DOP test, and by evaluating the ratio of the downstream and upstream particle concentrations.

In-place field tests with polydisperse DOP aerosol do not show the efficiency of the filters, but only reveal the presence of leaks in the system-scanning may be used if necessary to locate the leaks. If the penetration observed in the test is equivalent to the penetration established during factory testing, it can be inferred that the particle-removal efficiency of the system is equivalent to that of the individual filters. This is the basis for many persons identifying the in-place test as an efficiency test. The in-place test is not an efficiency test and should not be so considered.

\section{PENETRATION MEASURED WITH 'OWL' PHOTOMETERS}

The accuracy of the historical standard U.S. test method for certifying HEPA filters is in question (Hinds et al. 1979). There are two problems: I) the particle size distribution and 2) the response of the measuring instrumentation. Dioctyl phthalate (DOP) aerosols used in the test are not monodisperse (i.e., a single size). Furthermore, the particle-size analyzers used for DOP testing, called owls (see Appendix 3), can have the same owl reading for different particle-size distributions.

\section{PENETRATION MEASURED WITH MODERN PARTICLE DETECTORS}

Modern airborne-particle detection equipment can determine filter efficiency as a function of particle size. The new detection equipment is referenced in a recent standard (DOE 1988).

Replacement of the owl with modern particle-size spectrometers may lead to apparent large errors in filter penetration (Bergman and Biermann 1985). 
The instrument responses of modern particle-size spectrometers do not correspond to the owl photometer measurements. Since light-scattering response is a function of particle size, varying DOP size distributions affect instrument response. Also, HEPA penetration is a function of particle size. Hence, measured HEPA filter penetration depends on the light-scatteringinstrument response and on the HEPA filter penetration curve, both measured as a function of particle size. HEPA filter penetration for a heterodisperse (a) DOP aerosol may increase, decrease, or remain the same when compared with the filter penetration for monodisperse aerosols.

Bergman and Biermann (1985) also give an example where changes in the particle-size distribution result in similar instrument responses by both a photometer and an ow1. The calculations for the example are based on experimental HEPA filter penetration and photometer response curves. Heterodisperse DOP aerosols $\left(D_{\mathrm{cmd}}=0.19\right.$ and $\sigma_{\mathrm{g}}=1.4$, respectively, count-median diameter and geometric standard deviation) yield $24 \%$ lower penetrations than that for monodisperse DOP aerosols $\left(D_{\mathrm{cmd}}=0.3\right.$ and $\left.\sigma_{\mathrm{g}}=1.0\right)$. Bergman and Biermann report this as a small effect of the DOP heterodispersion on HEPA filter penetration. In this case, a small effect is predicted because the response function of the owl is similar to the response of the photometer.

Laser particle counters (LPCS) are used to investigate filter efficiency as a function of particle diameter. The sensitivity of some LPCs systems is greater than with photometers in DOP filter tests. Bergman et al. (1988) report a test procedure to evaluate filter penetrations as low as $10^{-9}$ for particle diameters as small as $0.1 \mathrm{~km}$. In comparison, the present U.S. nuclear filter certification test (DOP test) has a lower penetration limit of only $10^{-5}$.

The test procedure developed by Bergman et al. (1988) has much higher sensitivity than DOP tests, and avoids clogging the filter. The test procedure is a two-step process: 1) the test filter is challenged with a

(a) Heterodisperse means an aerosol which has a particle size distribution, i.e., many different particle diameters. Monodisperse means an aerosol containing only one particle diameter, i.e., a very narrow size distribution experimentally obtainable with state-of-the-art particle generation equipment for research applications. 
very high concentration of heterodisperse aerosol for a short time while passing a 11 or a significant portion of the filtered exhaust into an inflatable bag; 2) the aerosol concentration in the bag is measured using a laser particle counter sensitive to $0.07-\mu m$-diameter particles. The ratio of particle concentration in the bag to the concentration challenging the filter gives the filter penetration as a function of particle diameter. Bergman et al. also compared filter penetration measurements taken in the conventional direct-sampling method with the indirect bag-sampling method and found excellent agreement.

\section{ADDITIONAL DEVELOPMENTS FOR IN-PLACE TESTING METHODS}

In-place testing methods continue to be improved. Some of these techniques may be applicable to the Hanford Waste Vitrification Plant, especially for inclusion in the design of the selected option for air cleaning. Information on recent developments follows.

OOP test procedures require uniform airborne concentrations of DOP upstream of the filter system. A method to DOP test a series of large HEPA filter banks is described by Hanson (1983). This system provides a uniform concentration of DOP smoke within a $5-\mathrm{ft}$ space that exists between banks. He tested two different systems containing 28 and 42 HEPA filters, each having another bank of HEPA filters in series.

In-place testing also is needed for HEPA filters that are physically inaccessible or highly radioactive. Herman (1983) reports an in-place HEPA filter aerosol system applicable to HEPA filter systems where contact maintenance cannot be performed as required by other in-place type test systems. He tested the integrity of individual filter stages (banks) of multiple-stage HEPA filter systems.

Slow degradation of filter efficiency is evaluated by automaticcontinual versus periodic in-place testing. Advantages of a continuous monitoring system for HEPA filters are given by Kirchner et al. (1985). They report the design of a system using current technology. This system has 
three major improvements over current methods of filter testing and replacement. This system 1) realizes a cost savings by reducing the number of intact filters replaced unnecessarily, 2) provides a more accurate and quantitative measurement of filter performance than with existing testing methods, and 3) reduces personnel exposure to a radioactive environment by automatically performing most testing operations.

\section{REFERENCES}

ANSI-N101.1. 1972. Efficiency Testing of Air Cleaning Systems Containing Devices for Remova1 of Particles, ANSI Standard N101.1. American National Standards Institute, New York.

ANSI-N510. 1980. Testing of Nuclear Air-Cleaning Systems. ANSI Standard N510. American National Standards Institute, New York.

Bergman, W., and A. Biermann. 1985. "Effect of DOP Heterodispersion on HEPA-Filter-Penetration Measurements." In Proceedings of the 18th DOE Nuclear Air Cleaning Conference. CONF-840806, pp. 327-347. Available from National Technical Information Service, Springfield, Virginia.

Bergman, W., L. Foiles, C. Mariner, and M. Kincy. 1988. "New filter Efficiency Test for Future Nuclear Grade HEPA Filters." In Proceedings of the 20th DOE/NRC. Nuclear Air Cleaning Conference. NUREG/CP-0098, CONF880822, pp. 1189-1209. Available from National Technical Information Service, Springfield, Virginia.

Cambridge. 1989. Absolute Filter Testing. Bulletin 12-106. Cambridge Filter Corporation, Syracuse, New York.

DOE. 1988. Quality Assurance Testing of HEPA Filters. F 3-43, DOE Nuclear Energy Programs, Performance Assurance Office, Oak Ridge National Laboratory, Oak Ridge, Tennessee.

Hanson, W. D. 1983. "DOP Testing HEPA Filter Banks in Series." In Proceedings of the 17th DOE Nuclear Air Cleaning Conference. CONF-820833, pp. 882-894. Available from National Technical Information Service, Springfield, Virginia.

Herman, R. L. 1983. "In-place HEPA Filter Aerosol Test System." In Proceedings of the 17th DOE Nuclear Air Cleaning Conference. CONF-820833, pp. 847-866. Available from National Technical Information Service, Springfield, Virginia.

Hinds, W., M. First, D. Gibson, and D. Leith. 1979. "Size Distributions of "HOT DOP" Aerosol Produced by ATI-Q-127 Aerosol Generator." In Proceedings of the 15th DOE Nuclear Air Cleaning Conference. CONF-780819, pp. 1130-1144. Available from National Technical Information Service, Springfield, Virginta. 
Kirchner, K. N., C. M. Johnson, J. J. Lucerna, and R. L. Barnett. 1985. "In-situ Continuous Scanning High Efficiency Particulate Air (HEPA) Filter Monitoring System." In Proceedings of the 18th DOE Nuclear Air Cleaning Conference. CONF-840806, pp. 277-298. Available from National Technical Information Service, Springfield, Virginia. 


\section{DISTRIBUTION}

No. of

Copies

\section{OFFSITE}

12 DOE/Office of Scientific and Technical Information

3 DOE Office of Civilian Radioactive Waste Management Forrestal Building Washington, DC 20585

ATTN: L. H. Barrett, RW-33

D. E. Shelor, $R W-32$

R. Stein, RW-23

2 DOE Office of Defense Waste \& GTN Transportation Management Washington, DC 20545

ATTN: K. A. Chacey, DP- 123

T. B. Hindman, DP-12

3 DOE Office of Waste Operations Washington, DC 20545

ATTN: J. A. Coleman, EM-35

T. W. McIntosh, EM-343

H. F. Walter, EM-343

A. T. Clark

Division of Fuel Material Safety

Nuclear Regulatory Commission

Washington, DC 20555

V. Stello

office for the Executive

Director for Operations

Mail Station 17-621

Nuclear Regulatory Commission

Washington, DC 20555

R. N. Gibbons, Project Manager

Fluor Daniels, Inc.

3333 Michelson Drive

Irvine, California 92730
No. of

Copies

Sheldon Meyers

Environmental Protection Agency

Office of Radiation Programs (ANR-458)

401 M Street S.W.

Washington, OC 20460

P. A. Saxman

OOE Albuquerque Operations Office P.0. Box 5400

A1buquerque, NM 87185

W. McMullen

S. M. Stoller Corp.

4665 Indian School Rd. N. E. 104

Albuquerque, NM 87110-3930

E. Maestas

DOE West Valley Project

P.0. Box 191

West Valley, NY 14171

3 DOE Idaho Operations office

785 DOE Place

Idaho Falls, ID 83402

ATTN: C. R. Enos

M. W. Shupe

J. E. Solecki

F. T. Fong

DOE San Francisco Operations

1333 Broadway

0akland, CA 94612

M. R. Jugan

DOE Oak Ridge Operations Office P.0. Box E

Oak Ridge, TN 37830

W. T. Goldston

DOE Savannah River Operations Office

P.0. Box A

Aiken, SC 29801 
PNL - 739I

UC-721

No of

Copies

M. J. Steindler

Argonne National Laboratory

9700 South Cass Avenue

Argonne, IL 60439

C. S. Abrams

Argonne National Laboratory

P.0. Box 2528

Idaho Falls, ID 83401

2 Battelle Memorial Institute

Project Management Division 505 King Avenue

Columbus, $\mathrm{OH} 43201$

ATTN: W. A. Carbeiner

R. A. Nathan

L. D. Ramspott

Lawrence Livermore National Laboratory

University of California

P.0. Box 808

Livermore, CA 94550

D. T. Oakley, MS-J521

Los Alamos National Laboratory

P.0. Box 1663

Los Alamos, NM 87545

4 Oak Ridge National Laboratory

P.0. BoX Y

Oak Ridge, TN 37830

ATTN: W. D. Burch

R. T. Jubin

L. J. Mezga

D. W. Turner

2 Sandia Laboratories

P.0. Box 5800

Albuquerque, NM 87185

ATTN: R. W. Lynch

Technical Library
No of

Copies

W. C. Taylor, Project Director HWVP Project

UE\&C-Catalytic, Inc.

P.0. Box 10

Richland, WA 99352

J. R. Berreth

Westinghouse Idaho Nuclear

Co., Inc.

P.0. Box 4000

Idaho Falls, ID 83401

5 Westinghouse Savannah River Company

Savannah River Site

Aiken, SC 29801

ATTN: R. G. Baxter

M. D. Boersma 77341A

J. R. Knight $773 \mathrm{~A}$

M. J. Plodinec 773A

C. T. Randa 717042

A. D. Rodgers

MaiT Stop 2411

EG\&G Idaho

P.0. Box 1625

Idaho Falls, ID 83415

R. Shaw

Electric Power Research Institute

3412 Hillview Avenue

P.0. Box 10412

Palo Alto, CA 94303

8 West Valley Nuclear Services Company

P.0. Box 191

West Valley, NY 14171

ATTN: S. M. Barnes

R. R. Borisch

J. Buggy

D. E. Carl

R. L. Crocker

D. D. Daruwalla

J. M. Pope

R. A. Thomas 
No of

Copies

J. L. White, Chairman

- Energy Research \& Development Authority

Empire State Plaza

Albany, NY 12223

\section{ONSITE}

12 DOE Richland Operations Office

J. H. Anttonen, (5) A5-10

R. W. Brown, A5-53

M. J. Furman, A5-10

W. S. Ketola, A3-53

P. E. LaMont, A5-10

K. K. Lucas, A5-80

B. L. NicolT, A6-90

E. C. Norman, A5-51

18 Westinghouse Hanford Company

J. W. Bailey, G6-06

J. R. Baker, G6-06

P. Felise, G6-16

J. M. Henderson, G6-02

J. E. Irvin, G6-14

0. L. Kruger, G6-08

R. E. Larson, G6-16

W. C. Miller, G6-06

R. B. Morson, G6-06

J. A. MuTlal1y, G6-06

E. A. Nelson, G6-02

D. Smith, G6-16

R. A. Smith, G6-02

G. E. Stegen, G6-06

L. D. Swenson, G6-06

D. R. Taal, G6-12

E. T. Weber, G6-08

HWVP PRMC, H5-51
No of

Copies

1 Kaiser Engineers Hanford

G. C. Lengas, E6-32

34 Pacific Northwest Laboratory

C. R. Allen, G6-01

D. A. Cataldo, K4-12

C. C. Chapman, P7-41

R. M. Ecker, Sequim

M. R. Elmore, G6-01

J. W. Falco, K6-78

R. W. Goles, G6-01

J. M. Hales, K6-04

P. C. Hays, K6-86

D. K. Hilliard, K2-12

D. E. Larson, G6-01

J. L. McElroy, P7-46

W. T. Penne11, K6-98

J. M. Perez, Jr., P7-41

L. E. Rogers, P7-50

A. J. Schmidt, K2-12

G. A. Sehmel, (10) K4-06

G. J. Sevigny, G6-01

R. L. Skaggs, K6-77

Publishing Coordination

Technical Report Files (5) 
